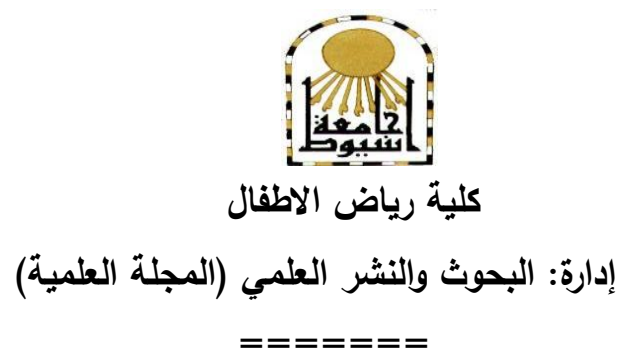

\title{
أثر تطبيق تجربة نظام التعليم اليابانى على التعليم الصصرى فى صناعة طفل المتقبل
}

إعـــــاد

د. راندة أصمد شاهين

رئيس الإدارة المركزية

لرياض الأطفال والتعليم الأساسى

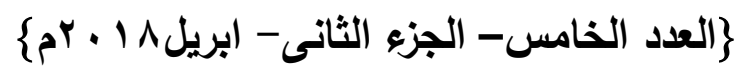


حثت الديانات السماوية على الإتقان والإخلاص في العمل كمدخل لبناء مجتمع قوى متماسك ومن الآيات القرآنية الكريمة التي تعزز ذلك الالتزام والاتقان قوله تعالى"وَقُلِلِ

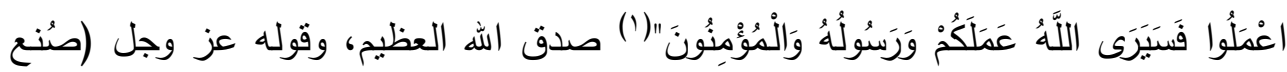
الله الذي أثقن كل شيء إنه خبير بما تفطلون)(؟) وقوله سبحانه" إن الذين آمنوا وعملوا

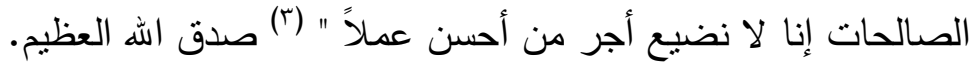

ويركز التعليم اليابانى على الأداء بطريقة صحيحة، وباسلوب نموذجي ومثالي يتجنب تبديد الموارد أو سوء استغلالها، ويرضي المستفيدين ويدعم الابتكار والتجديد, وقد وضعت بعض السياسات والاستراتيجيات والانشطة التى ترتقى بالتعليمية للتنافسية ومواجهة

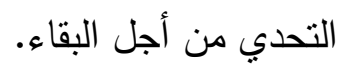

يعد التعليم الياباني تعليم تعدد ومتتوع يفي بحاجات مجتمعه، ويخرج اليد الماهرة

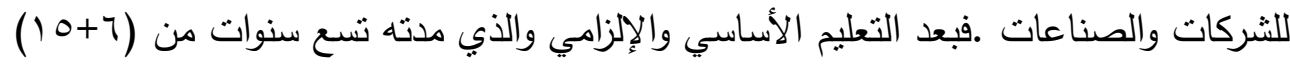
يأني التعليم الثانوي، والذي يتكون من عدة مسارات (إبراهيم، ؟ + . rم)

\section{مشكلة الاراسة:}

مع ازدياد أهمية التعليم لدى الدول العربية بصفة عامة، و مصر بصفة خاصة ورغم رصد المبالغ الطائلة من ميزانية مصر لرفع شأن المواطن المصريه من خلادل برامج التعليم

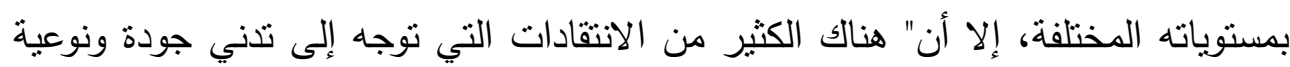

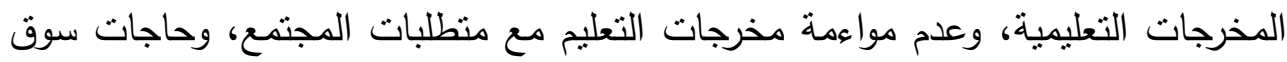
العمل وارتفاع تكلفة التعليم وزيادة الهرر المالى والتربوي في المؤسسات التعليمية" (؛).

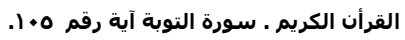

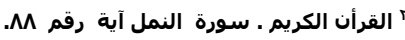

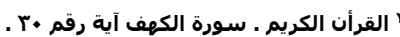

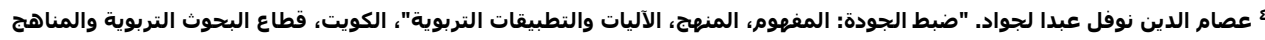

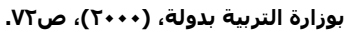


أدى ذلك إلى ظهور توجـه قوي يرمسي إلـي السـي الجـاد للارتقاء بكفـاءة النظـام

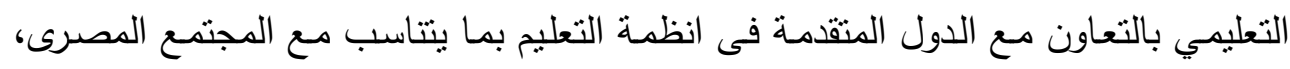

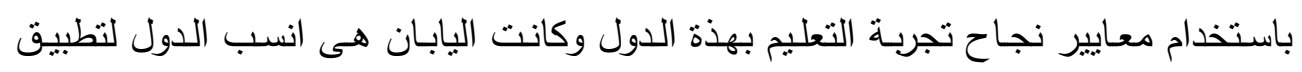

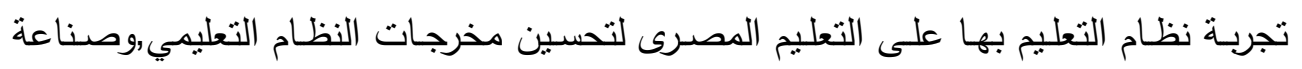
طفل المستقبل، وأثز ذلك على الأمن القومي المصري.

\section{أسئلة الدراسةة}

وفي ضوء ذللك يمكن صياغة المشكلة في السؤال التالي:

1- ما المقصود بمرحلة التعليم الأساسى؟

r - ما هى التجربة المصرية اليابانية ومفهومها وتأثيراتها ؟

r- لماذا الإهنمام بهذه التجربة فى هذا التوقيت ؟

ع - مـا الذى تهدف إليـه التجربـة المصـرية اليابانيـة واثر ذلك على الأمسن القومى

المصرى ؟

ه- هـل تـؤثر تجربـة التعليم اليابـانى بمـارس التعليم الاساسـى المصـرية على لـى

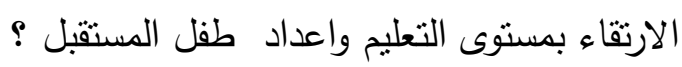

منطلقات الدراسة:

1- يزداد الاهنمام يوماً بعد آخر بالتربية كوحدة من أهم أدوات البناء الحضاري

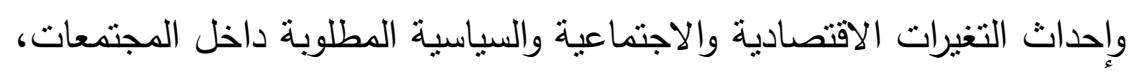

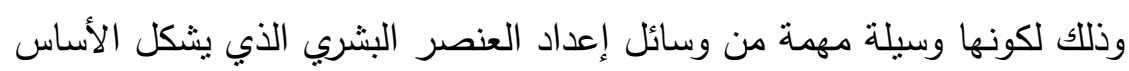
في عملية التتمية الاقتصادية والاجتماعية.

r- وتظهر اهميتها بسبب التغير والتطور المستمرين في عالم تتتامى فيه الأفكار

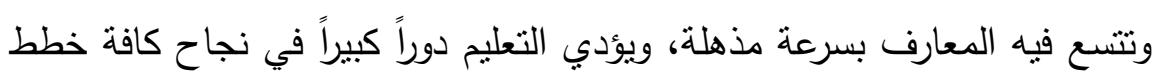


التتمية بوصفة بمثل عنصراً فاعلاً لتحقيق هذا التقدم، وهكذا بذلت الجهود وما تزال تبذل من أجل تطور التعليم ورفع كفايته.

r- للتعليم والثقافة اثر كبير ومباشر في المجال الاقتصادي، حيث تعد إنتاجية الفرد أحد مؤشرات قياس تقدم الدول أو تاخرها وكلما ارتفع هذا المعدل دل على تقدم

$$
\text { الدولة . }
$$

ع- يأتي تقدم الدول فى التعليم بداية، لاعداد الثخصية المثقفة المنتجه المبدعه ولديه خبرات ومواهب تؤدى الى رقي الدوله المصاف الدول المتقدمة، خاصة لأدة في ظل ثورة المعلومات وتكنولوجيا الإيصالات، وازدياد التكتلات العالمية الاقتصادية بما تحمله من قدرة على التميز في الإنتاج والمنافسة. 0- مصر أمامها الكثير من التحديات الاقتصادية حتى تسنطيع أن تصل إلى إلى

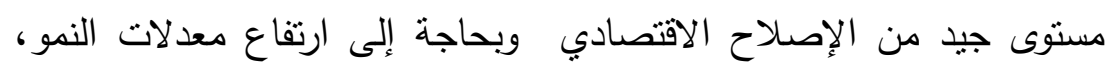

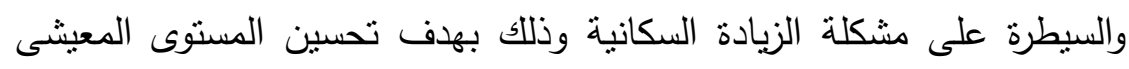
• والرقى

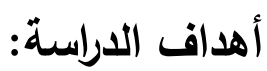

• تهدف الدراسة الحالية إلى إظهار أثر تطبيق نظام تجربة التعليم اليابانى في

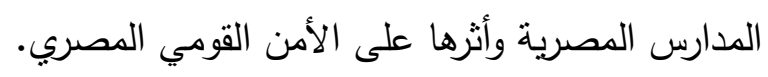

فاعلية دور المعلم فى تطبيق الانشطة التعليمية والتربوية بالمدارس المصرية. توضيح الأثر الإيجابي لتطبيق هذه الأنشطة (التوكانسو) في المدارس المصرية على الارتقاء بمستوى التعليم وصناعة طفل المستقبل. • لفت انظار أولياء الامور الى أهمية تفعيل دور الانشطة التربوية في التعليم للمساهمة في الارتقاء بمستوى التلميذ والتعليم. لهيه الهمريه 
أهمية الدراسة:

- - تظهر أهمية الدراسة الحالية في تعرضها لأحد الموضوعات الهامة المعنية بتطوير التعليم وأثر ذلـك على الأمسن القومى المصـرى مـن مختلف مجالاتـة السياسية

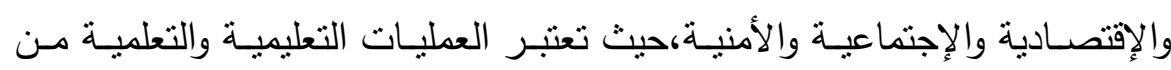
أخطر الأسلحة المعاصرة فى القرن الواحد والعشرين فهى قادرة على تغيير أو دعم

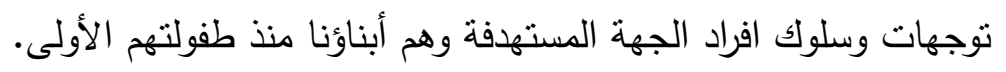
- ت تتاولها لنقاط بحثيـة جديدة تتعلق بأهميـة دراسـة دور التجربـة المصـرية اليابانيـة

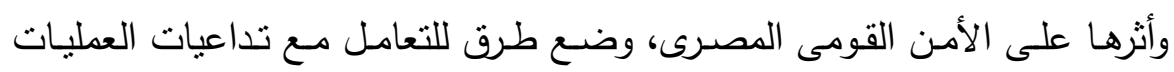
التعليمية والتعلمية في مدارس مرحلة التعليم الأساسى .

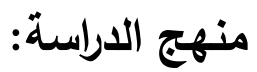

- المنهج الوصفي هو المنهج المناسب لطبيعة مشكلة البحث وأهدافه، وصفاً وتحليلاً

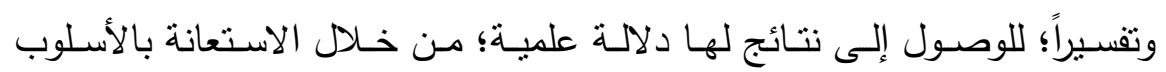
الإحصائي المناسب، عند القيام بالدراسة الميدانية.

- ـ ويسـتخدم المـنهج الوصـفي فـي دراســة الأوضـاع الراهنـة للظـواهر مـن حيـث

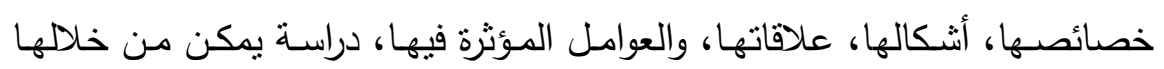

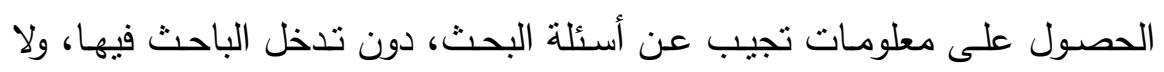

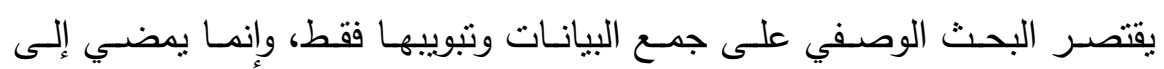

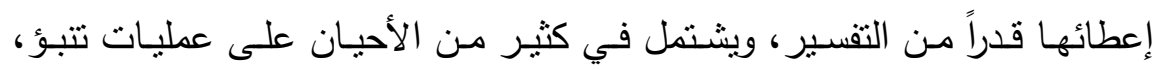
لمستقبل الظواهر والأحداث التي يدرسها.

\section{خطوات الدراسة:}

تحقيقا لتسـاؤلات الدراسـة والوصـول الى الاهداف الرئيسية مـن اعدادها سيتم تتـاول الدراسة الحالية من خلا الآتي: 
أولاً: تحديد الإطار العام للاراسة والمتمثل في المقدمة، مشكلة الدراسة وتساؤلاتها، ألهمية، الأهداف، المنطلقات.

\section{ثانياً: عرض الدراسات السابقة ذات الصلية بالموضوع.}

ثالثاً: الإطار النظري الذي يحتوي على تعريف ومفهوم مرحلة التعليم الأساسي ثم

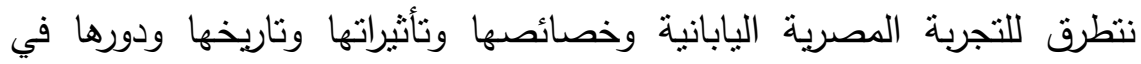

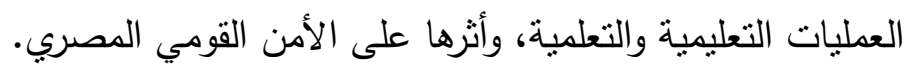
رابعاً: الاستفادة من التجربة اليابانية لإصلاح التعليم في مصر خامساً: ملخص الدراسة. سادساً: هم المراجع المستخدمة، وذلك على النحو التالي: ا

توجد بعض الدراسات السابقة التى تفيد فى هذا المجال على النحو التالى : - الدراسات التى نتاولت مستوى التعليم العام و مرحلة التعليم الأساسى. -

أولاً : دراسات تناولت مستوى التعليم العام و مرحلة التعليم الأساسى 1- أ.د./عبد الله بيومى،"متطلبـات تحقيق التمكين الاجتمـاعى فى مرحلـة التعليم الأساسى"(دراسة ميدانية) (०). المركز القومى للبحوث التربوية وإلتنمية 2013 كثفت الدراسة الحقائق حول أثنكال عدم التمكين والمعوقات التى تحول دون ذلك، وتأثير الفقر على تحقيق الاستيعاب الكامل وزيادة نسب التسرب والرسوب وضعف وانف البيئة التمكينية الميسرة للتعلمككما ان الدراسة تحاول علاج عدة قضايا منها: 
• متطلبات تمكين جميع الأطفال من الالتحاق بتعليم أساسى جيد مجانى وإلزامى

$$
\text { وإكماله حتى نهايتة. }
$$

توسيع نطاق التعليم الأساسى للجميع وتحقيق تكافؤ الفرص والوصول إلى الفئات

$$
\text { المهيشة. }
$$

• تقليل تأثثير الفقر على تمكين تلاميذ مرحلة التعليم الأساسى.

وقد هدفت الدراسة إلى الوقوف على الصعوبات والمعوقات التى تواجه تحقيق

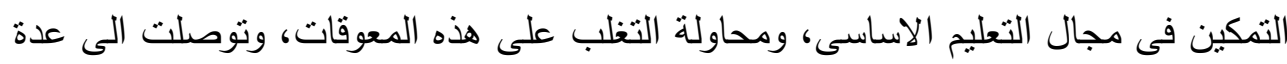

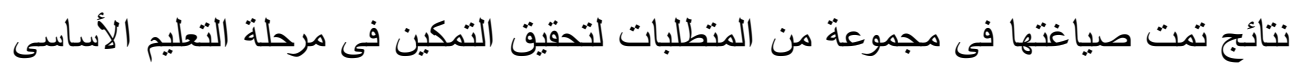
كالآتى:-

• إعداد خريطة بأهداف واضحة ومواعيد نهائية محددة للتصدى للتسرب من التعليم

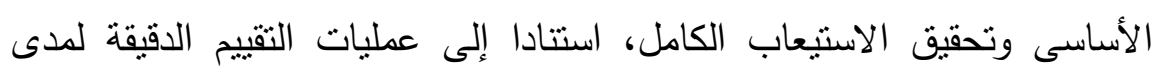

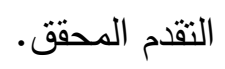

• أن تكون السياسات والتدابير التشريعية المطبقة فى مجال التعليم الأساسى شاملة واستيعابية ومتكاملة وتغطى وتربط جميع عناصر التعليم والتعلم، لمعالجة أوجه

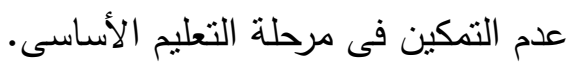
• تقديم الدعم المالى للتركيز بصورة منظمة على الفئات المحرومة فى جميع سياسات

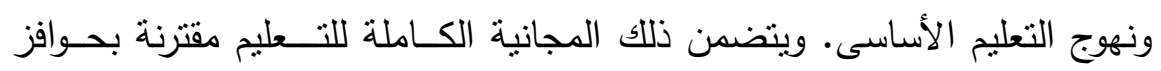
للتعلم لتمكين التلاميذ من الالتحاق.

ه القضاء على جميع أثنكال التمييز ضد الفنيات كما جاء في المواثثق الوطنية

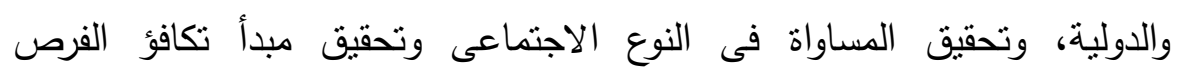

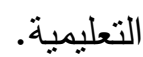


r- : أ.د/عايدة عباس أبو غريب،"دراسـة ميدانيسة لاستخدام الكتب المدرسية بمرحلـة

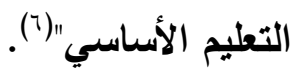

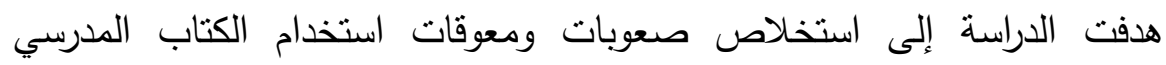

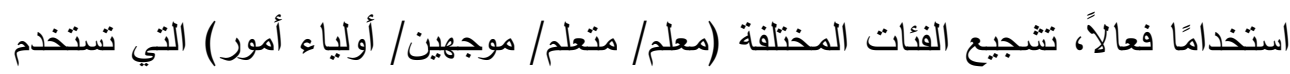

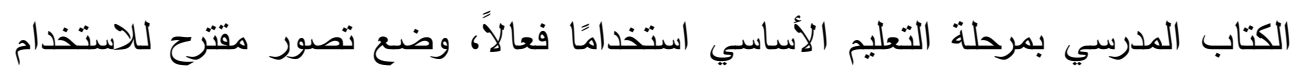

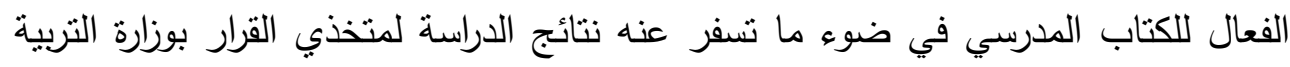

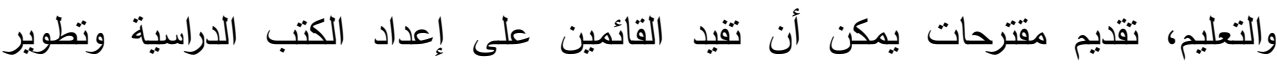
المناهجهو تقدم الدراسة مجموعة من التوصيات منها:

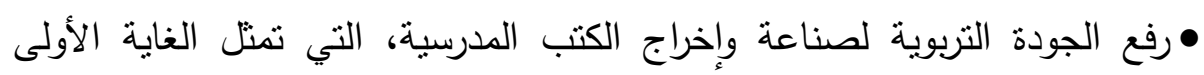

$$
\text { لإصلاح التعليم وتطويره. }
$$

تطوير المنافسة بين المؤلفين والنانشرين والمبدعين بناء على المعايير والمواصفات

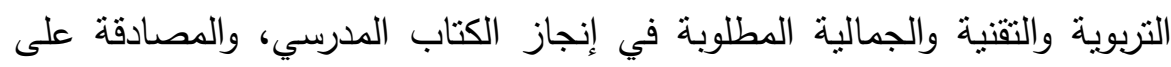

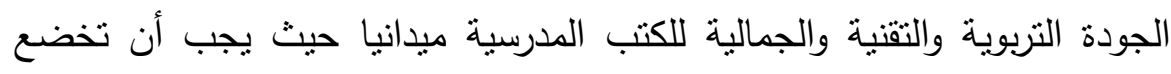

$$
\text { مشروعات الكتب لنقويمات عديدة (مرحلية ونهائية). }
$$

ץ- أ.د./ سعيد جميل سليمان،" الصعويات التي تواجه الدارس الابتدائية في مصر في

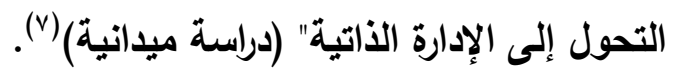

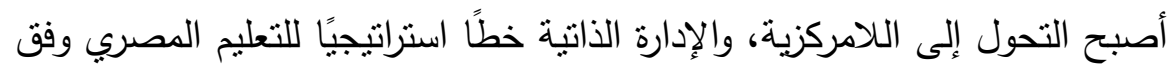

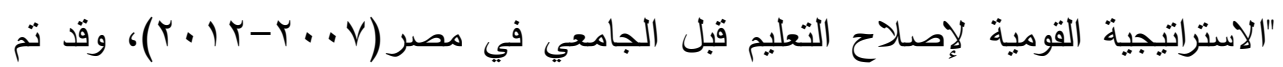

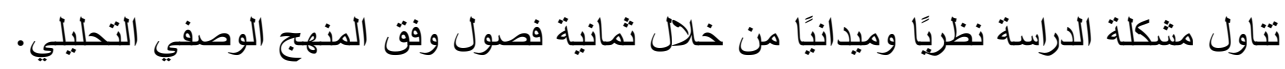

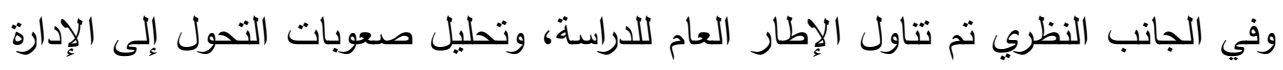
الذاتية في السياقات المختلفة، كما أجريت دراسة ميدانية باستخدام استيان استطلاع رأي الإني

أ.د/عادة عصاس أبو غرس،"دراسة ميدانية لاستخدام الكتب المدرسية بمرحلة التعليم الأساسى".المركز القومى للبحوث

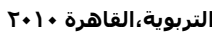
أ.د/سعيد جميل سليمان،"الصعوبات التي تواجه المدارس الإبة الابتدائية في مصر في التحول إلى الإدارة الذاتية"،(دراسة

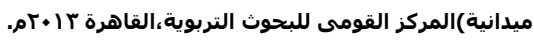


طبق على عينة من (0؛) فردًا من معلمي الددارس الابتدائية، ومديري الددارس،

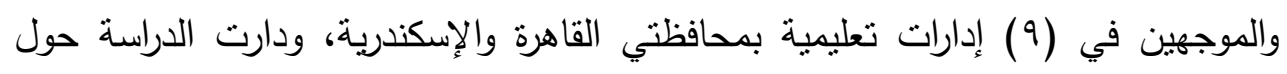

ثلاثة محاور رئيسة:

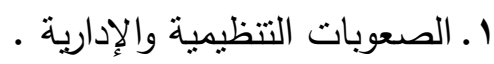

r ب الصعوبات البشرية والمادية.

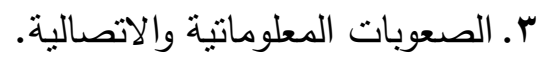

وقد تم تفسير نتائج الدراسة الميدانية، والتوصل لتوصيات كفيلة بمعاونة هذه

المدارس على مواجهة الصعوبات.

ع - أ. د.// محمد السيد حسونه،"التخطيط للوفاء بالاحتياجات التعليمية للقرى الأكثر

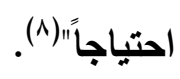

مسألة أهمية التعليم لم تعد محل جدل فى أى منطقة بالعالم فالتجارب المعاصرة

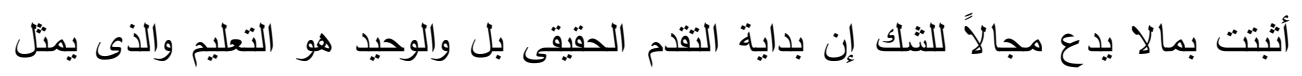

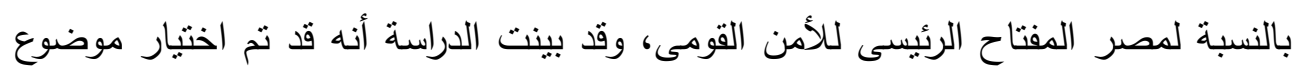

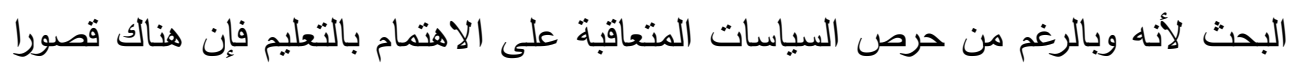

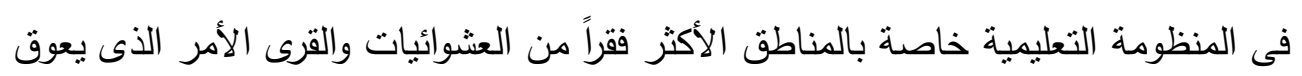

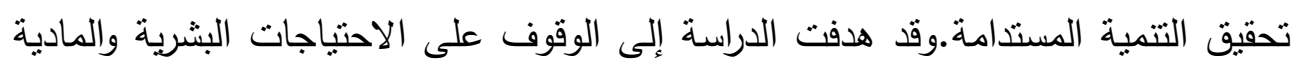
للوفاء بهذه الاحتياجات واستخدم فى إجراء البحث المنهج الوصفى بتقنياته العلمية باستخدام استمارة استطلاع رأى المديرين والنظار والمعلمين للوقوف على هذه الاحتياجات من الميدان على أرض الواقع، وتم النطبيق فى ست محافظات هى الثرقية والبحيرة والجيزة والفيوم

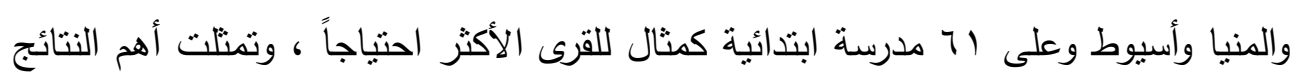
فيما بلى

^ أ. د. محمد السيد حسونه،"التخطيـط للوفاء بالاحتياجات التعليمية للقرى الأكثر احتياحاً"، المركز القومى للبحوث التربوية، القاهرة، 
1. فيما يتعلق بالموارد البشرية:

ه الاعتماد على كليات التربية باعتبارها المصدر الرئيسى لإعداد المعلمين منع

$$
\text { وتتوع المؤهلات. }
$$

تكليف إدارات التتسيق بإجراء مراجعة دقيقة لتحقيق التوزيع العادل وعلاج سوء

توزيع المعلمين.

r. - فيما يتعلق بالمتطلبات المادية:

اتخاذ إجراءات فاعلة من هيئة الأبنية التعليمية بإداراتها المتخصصة لإعداد خطط

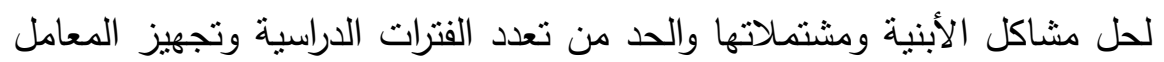

$$
\text { وإجراء الصيانة الدورية . }
$$

توفير عناصر أمن للمدارس مع توفير أجهزة وأدوات الإطفاء لتأمينها ضد أخطار

$$
\text { الحريق. }
$$

توفير التغذية لتلاميذ المدارس خاصة فى الفترة المسائية.

• ضمان وصول الكتب المدرسية فى المواعيد المقررة مع توفير وسائل النقل اللازمة

لذلك.

ه- نوال أحمد مفهوم "خبرة العمل" وتطبيقاته في مرحلة التعليم الأساسي في مصر"دراسة

نمائية" (9).

هدفت الدراسة إلى تعزيز مفهوم خبرة العمل في التعليم المصري على اعتبار أن

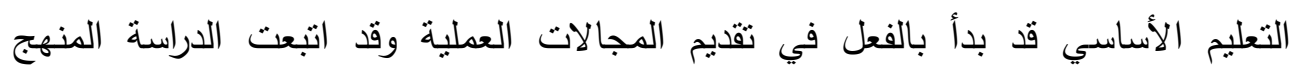

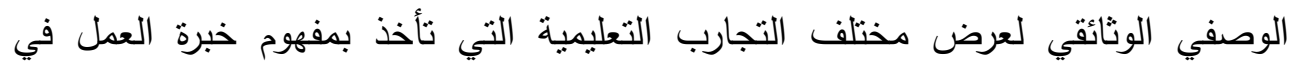
التعليم، مع استخدام أسلوب التحليل الفلسفي لتحليل مفهوم خبرة العمل والمفاهيم المرتبطة بها.وقد توصلت الدراسة إلى نتائج من أبرزها :

" نوال أحمد،" مفهوم خبرة العمل" وتطبيقاته في مرحلة التعليم الأساسى في مصر" "دراسة نمائية،المركز القومى للبحوث التربوية، 
الجهود التي قامت بها وزارة التربية والتعليم في مجال التربية للعمل في التعليم الأساسي، تبين أنه لم تكن هناك برامج واضحة تعمل من خلالها وظيفة التربية

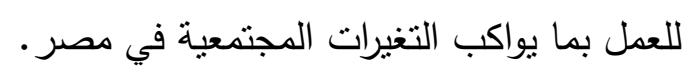
غالبية تجارب وصيغ التربية للعمل في مصر في إطار التعليم الأساسي حال دون عملها بفعالية مجموعة من العوامل التي يمكن من خلالها أن تحقق التربية

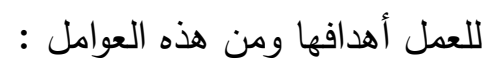

أ) قلة اهتمام القائمين على العملية التعليمية بأهدافها العامة والخاصة

والتركيز على التلقين والاستظهار .

ب) كثرة التعديلات الجزئية والهامشية والمقررات الدراسية تحت مسمى التطوير ثانياً:- دراسات تناولت تجربة التعليم اليابانى •

\section{1 - :عبد الغتي عبود "التربية العربية المقارنة منهج وتطبيق" (·').}

كان نظـام التعليم قبل الحرب العالميـة الثانيـة يتشـعب إلى خمسـة فروع بعد ست

$$
\text { سنوات من التعليم الأولي : النعليم }
$$

أهمها الفرع الأكاديمي إذ كان يحظى بمكانة كبيرة لأنه يؤدي إلى الجامعة ومن

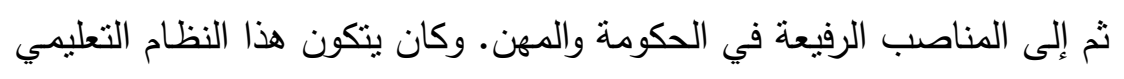

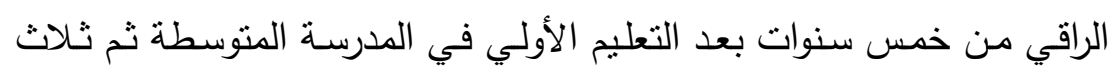
سنوات في المدرسة العالية ثم ثناث سنوات في الجامعة وفي نهاية كل مرحلة كان يوجد امتحان قاس للاخول في المرحلة التالية.

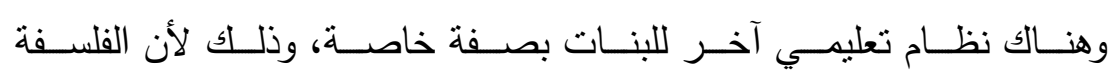

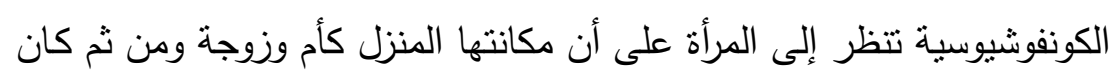

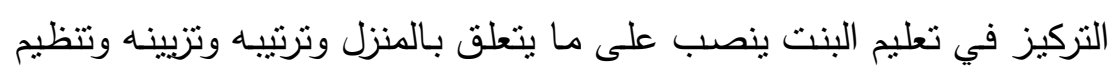
حفلات الثاي والعناية بالطفل وغيرها

• | ع9०" . عبد الغني عبود،" التربية العربية المقارنة منهج وتطبيق " "، القاهرة 
أمسا حديثا يبدأ السلم التعليمي بالحضـانة و ريـاض الأطفال ثم تأتي بعد ذلك المدرسة الابتدائية ومدتها ست سنوات وتتقسم إلى مرحلتين مرحلة ثانوية دنبا ومرحلة ثانوية عليا وكل منهما ثنلاث سنوات

r- : إسماعيل احمد حجي " التربية المقارنة" نظام التعليم فى اليابان ('). للالمام بكافة أبعاد الدور الذي تقوم بـه المؤسسة التعليمية في تثكيل حياة إنسان

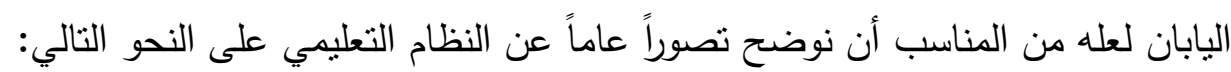
1. يقوم النظام التعليمي في اليابان والذي يستوعب مائة في المائة من السكان

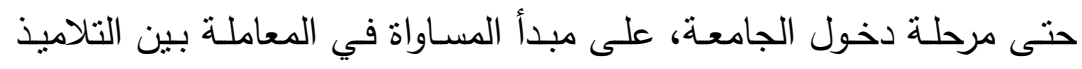

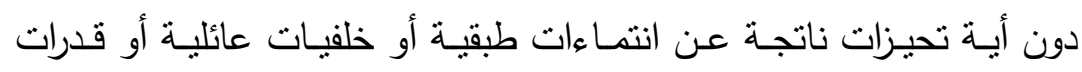
ذهنية ـ والافتراض الأساسي للنظام التعليمي هو أن كافة التلاميذ يتساوون

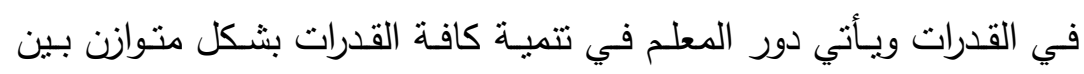
الجميع

r. نتيجة لهذا الافتراض الأساسي بالمساواة فإن الانتقال من مرحلة تعليمية إلى مرحلة تعليمية أعلى منذ بدايـة التعليم الابتدائي. وحتى دخول الجامعة ينت بشكل تلقائي مضمون فلا رسوب للتلاميذ، ومن يدخل بضمن الخروج منها

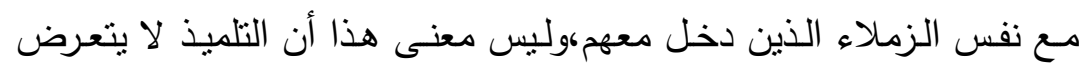

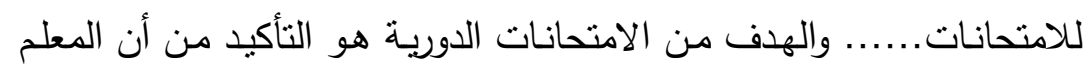

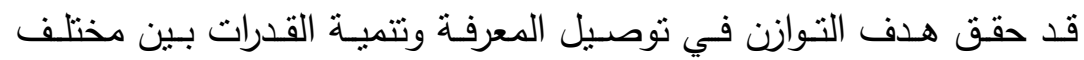
التلاميذ.

عند مستوى التعليم الجامعي يختلف الوضع فيما يتعلق بالمساواة والامتحانات والانتقال من صف لآخر هنا تبدأ المنافسة في الامتحانات والقدرات لدخول الجامعات

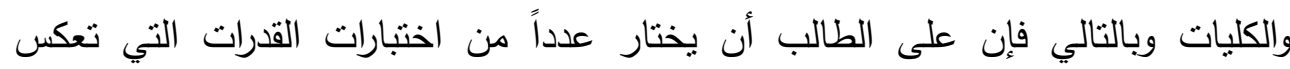

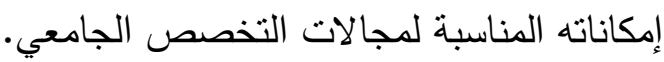

" ११^". إسماعيل احمد حجي،" التربية المقارنة" نظام التعليم فى اليابان" "، القاهرة 
r- : إدوارد، أبو شاحب "التربية في اليابان المعاصر"(r'). هناك مجالات ستة للدراسة في جميع أنحاء اليابان وهذه المجالات هي الصحة -

$$
\text { المجتمع - الطبيعة- اللغة - الموسيقى - الفن. }
$$

أما اليوم المدرسي فيبدأ في الثامنة والنصف صباحاً، حيث يفتتحون يومهم بفترة من

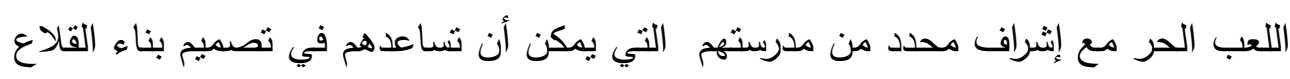

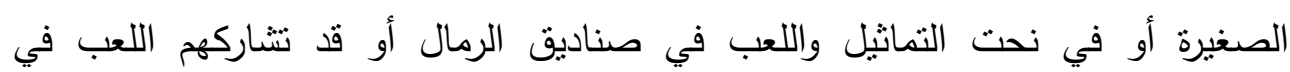

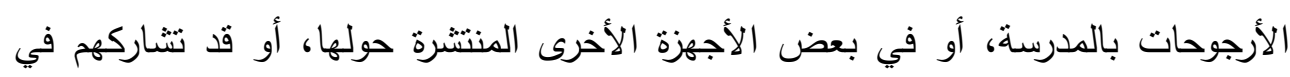
الكثير والعديد من أوجه النشاط الأخرى، وتتتهي فترة اللعب الحر ويعطى الأطفال فترة قصيرة يذهبون فيها لدورات المياه، يدعى إلى اجتماع يحضره المعلم لتحية الأطفال وتغني ولئي

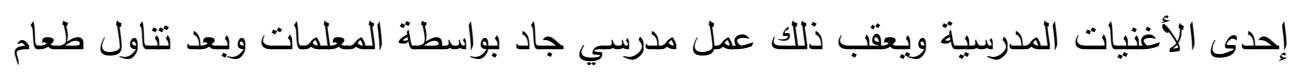
الغذاء يمنح الطلاب نصف ساعة للعب الحر وبعد لحظات يجمعون حاجاتهم وينظفون حجرات دراستهم بتطبيق بعض انشطة التوكاتسو التى تمارس فى الفصول بهدف خلق بيئة

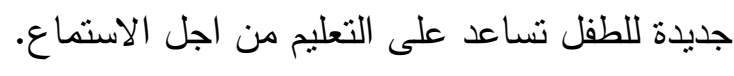

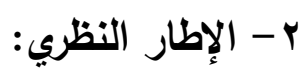

يتم تناوله من خلال المحاور الثلاثة التالية المحور الأول: التعليم الأساسي:

مفهوم مرحلة التعليم الأساسى (1):

هو :تعليم موحد توفره الدولة لجميع الأطفال ممن هم سن الددرسة , مدته تسع سنوات

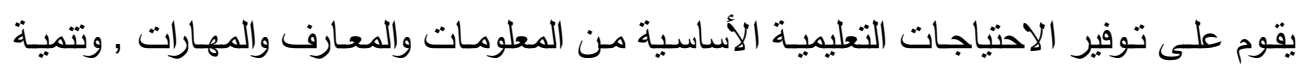

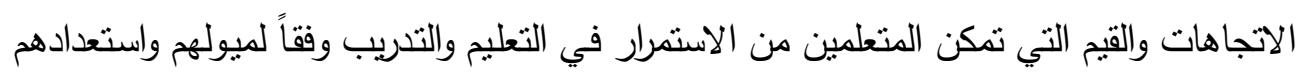

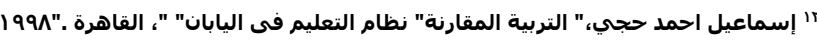

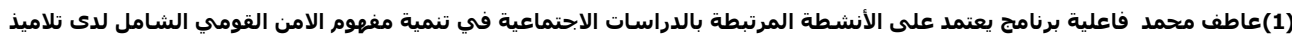

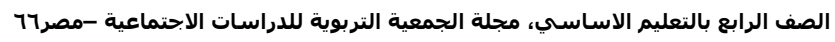


وقدراتهم التي يهدف هذا التعليم إلى تتميتهـا لمواجهـة تحديات وظـروف الحاضـر وتطلعـات المستقبل, في إطار التتمية المجتمعية الثاملة، ويتصف هذا التعليم بالآتي:

- تعليم موحد للجميع, على أسـاس أنهم أعضـاء في مجتمع واحد تجمعهم أهداف

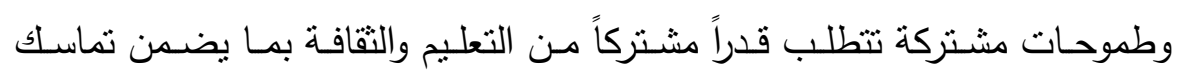
المجتمع وفق هويته الثقافية العربية والدينية. - - تعليم مدتـه تسـع سـوات يتواعم مـع التوجهات التربويـة الحديثة ومتطلبـات الحيـاة

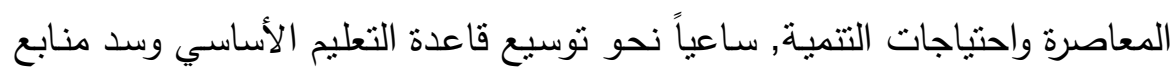

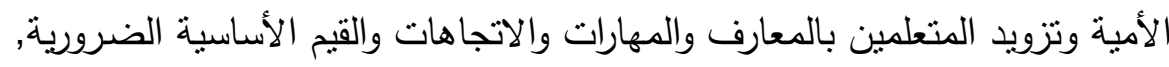

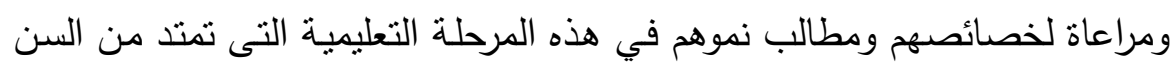
السادسة حتى السن الخامسة عشر . - تعليم يتصف بالثمولية من حيث تتمية جميع جوانب شخصية المتعلم في إطار

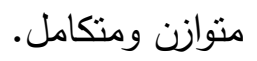
- تعليم يهنتم بالربط بين النظريـة والتطبيق والفكر والعهل والتعليم والحياة وفق مبدأ تكامل الخبرة .

- تعليم يسـى نحو إكسـاب المتعلم مهارات التعلم الذاتي في إطـار مفهوم التربيـة

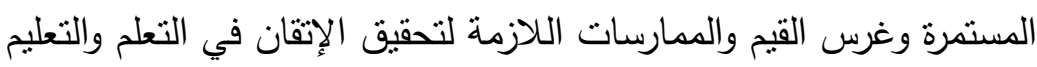
- تعليم يتصف بالمرونة في توجيه مخرجاته حيث يعد المتعلم لمواصلة التعليم بالمراحل

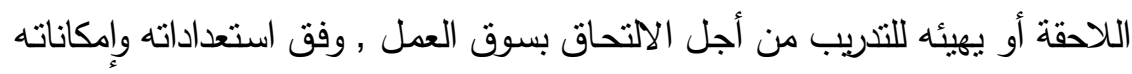
وكفاياته.

- تعليم يستهدف إعداد المتعلمين للإسهام في التتمية المجتمعية الثناملة.

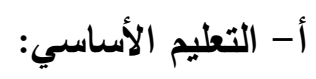

تحتل مرحلـة التعليم الأساسي مكان الصدارة بالنسبة لمراحل التعليم

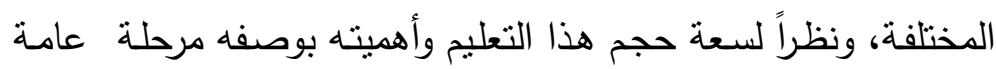




\section{المجلة العلمية لكلية رياض الاطفال - جامعة اسيوط}

أساسية ينبغي أن يحصل عليها كل أبناء الثنب، ويعد الحد الأدنى

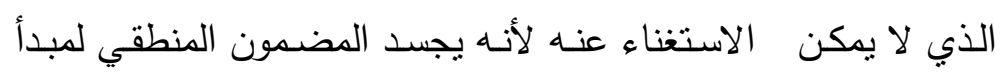
تكافؤ الفرص التعليمية في مرحلة الطفولة.

فهـي الأسـاس لنهـو الثخصـية الإنسـانية وتتـكيل سـماتها وتطويرهـا

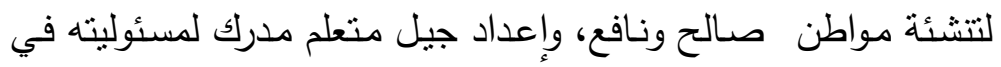
مواجهة التحديات المستقبلية .

إضـافة إلـى أن مرحلـة التعليم الأساسـي تعـد مرحلـة إلزاميـة يحصـل

المتعلم من خلالها على الحد الأدنى من المعارف والمهارات(').

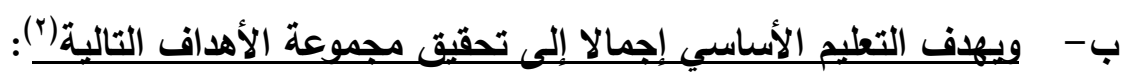

(1) تتمية مختلف جوانب شخصية المتعلم تتمية شاملة متكاملة.

(ץ) يغرس الانتماء الوطني لدي المتعلم وتتمية قدرته على التفاعل مع العالم

$$
\text { المحيط به. }
$$

(ץ) إكساب المتعلم المهارات اللازمة للحياة وذللك بتتمية كفايات الاتصال

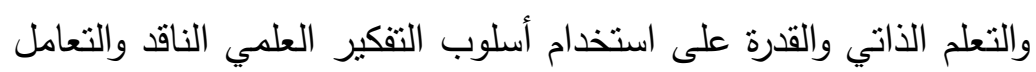

$$
\text { مع العلوم والتقانات المعاصرة. }
$$

(؛ ) إكساب المتعلم قيم العمل والإنتاج والإتقان والمشاركة في الحياة العامة والقدرة

على التكيف مع مستجدات العصر والتعامل مع مشكلاته بوعي ودراية

والمحافظة على البيئة واستثمار مواردها وحسن استغلال وقت الفراغ.

$$
\text { (0) التقليل من نسبة التسرب بين الطلاب. }
$$

$$
\text { (†) سد منابع الأمية، ورفع مدارك ومعارف الطلاب. }
$$

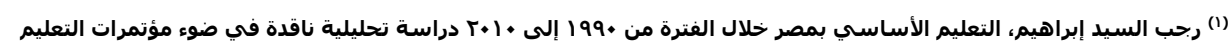

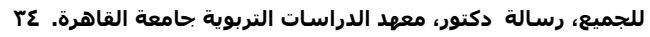

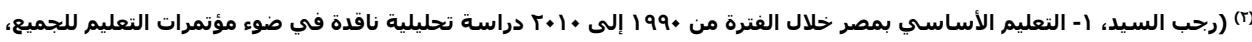

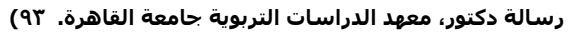


أ- مفهوم الأمن القومي (־) :

يعتبر الأمن من الحاجات الأساسية للبشر ومن أهم الضروريات الفطرية عند

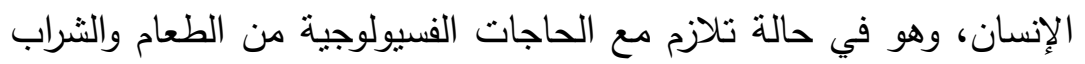

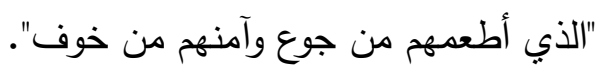

الأمن لغة : يعني الطمأنينة والسكينة ــوفي المعجم الوسيط أمن أمنا

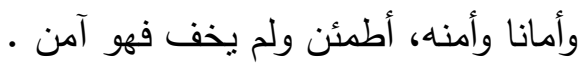

أمن : الأمان والأمانة بمعنى واحد، وقد أمنت فأنا آمن، أمنت غيري :

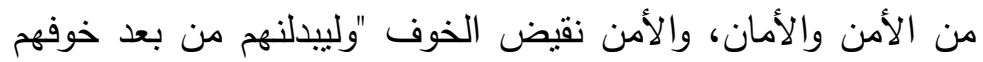
أمنا" والخوف يعني التهديد الثامل، سواء كان تهديدا عسكريا أو تون سياسيا أو اقتصاديا أو اجتماعيا، وبسبب عوامل داخلية أو خارجية الأمن اصطلاحا : بعني الإجراءات التأمينية التي تتخذ لحفظ أسرار الدولة وتأمين أفرادها ومنشآتها الحيوية وقيمها ومصالحها القومية من الأخطار والمهددات الداخلية والخارجية .

وهناك من يرى أن الأمن هو الحالة التي تتوفر حتى لا يقع في البلاد

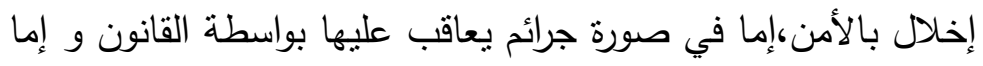

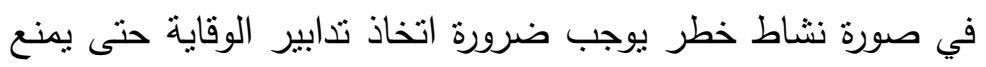

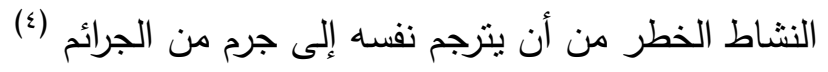

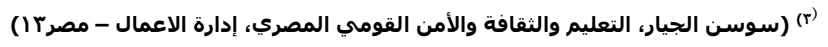
(ع) (هاشم محمد، استراتيجية علاقة التعليم بالأمن في الوطن العربي الأكاديمية العليا للدراسات الاستراتيجية والامنية السودان/ 
المفاهيم والنظريات (') إن كلمة الأمن تعني بالضرورة إحساس الفرد

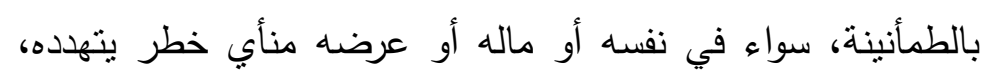

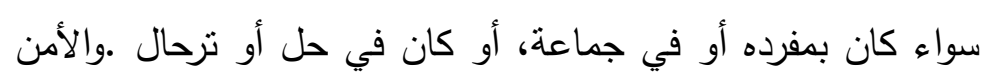

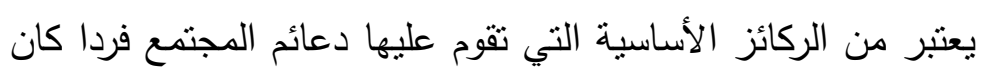

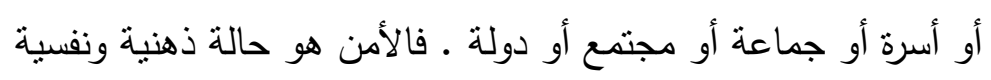
وعقلية.

ويقصد بمفهوم الأمن : توفير منطلبات الأمن والسكينة للإنسان، وصون الحياة الاجتماعية بالثكل الذي يضمن حسن سيرها وانتظامها

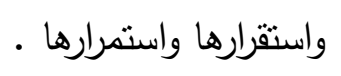

\section{ب- الأمن بمفهومه العام يتحدد في عنصرين أساسيين هما(؟):} تحقيق متطلبات التتمية الثاملة الاجتماعية والاقتصادية.

$$
\text { ضمان مقدرة الدولة في اتخاذ القرار السياسي. }
$$

\section{التعليم والأمن القومي(") :}

أ- فى ظل التحديات الخطيرة التي تمر بها البلاد لا أحد ينكر ارتباط التعليم

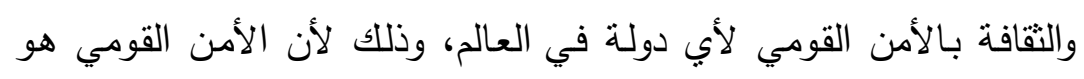

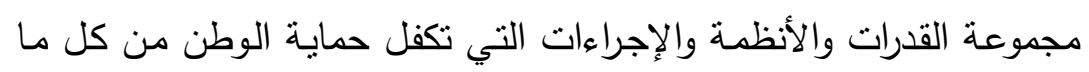
يتهدده من أخطار منظورة أو محتملة تهدد استقراره و رفاهيته وسلامة أراضيه

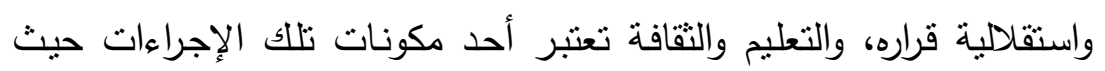

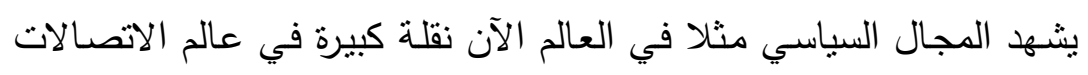
وتكنولوجيا المعلومات، انتشار قيم الديمقراطية والحرية وحقوق الإنسان

(1) (عاطف محمد، فاعلية برنامج يعتمد على الأنشطة المرتبطة بالدراسات الاحتماعية في تنمية مفهوم الامن القومى الشامل لدى الراسي

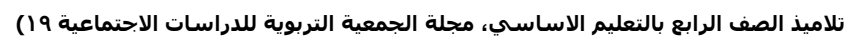

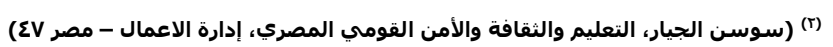

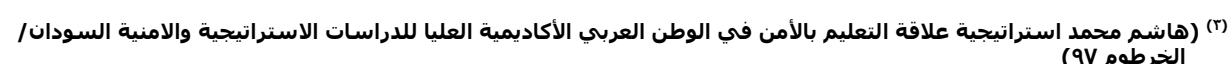


والمطالبة بالإصـلاح في شتى جوانبه، وفى ذات الوقت يعانى من الإرهاب وانتشار أسلحة الدمار الثامل وزيادة موجات التطرف والإدمان.

ب- لذا فإنتا نحتاج في المرحلة المقبلة إلى سياسة ثقافية وتعليمية واعية وهى

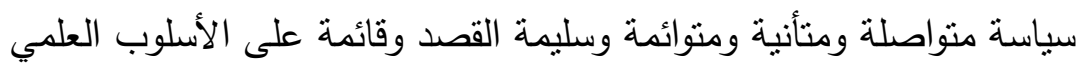

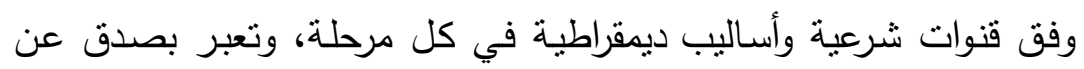

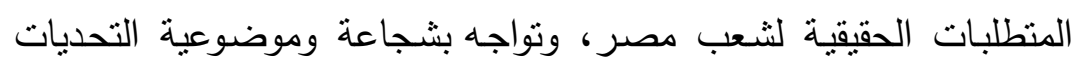
العالمية التي يتعرض لها .

ج- - تثقيف وتعليم الطالب تعليما جيدا قائما على التربية التي تتمى ملكاته في

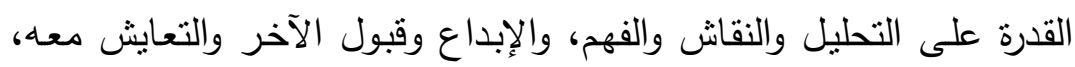

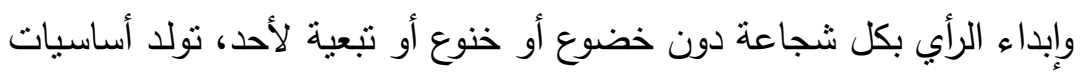

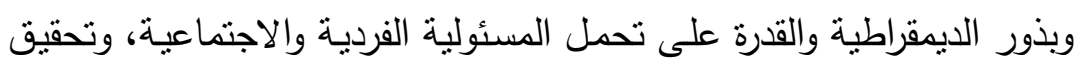
السلام الاجتماعي في الوطن.

دور إستراتيجيات التعليم على الأمن(')

أ- يعتبر التعليم أحد مفاتيح التتمية الرئيسة إذ إنه من أساسيات التغيير

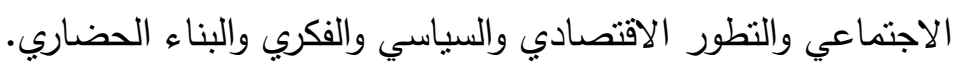
ب- كما يعتبر المدخل الصحيح للتنمية الثاملة القائمة على مهارات الفرد وخبراته العلمية والتطبيقية إذ إنه يمكن الفرد من اكتساب أدوات التعلم

ومضامينه وتوظيفها في الإسهام في التتمية والاستخدام المرشد لعائداتها. ج- التعليم يمكن الفرد أيضاً من تلبية حاجاته الذاتية والاجتماعية والفكرية وبناء قدراته الإنتاجية وتمكينه من الخروج من دائرة الفقر والفاقة.

(1) (عاطف محمد فاعلية برنامج يعتمد على الأنشطة المرتبطة بالدراسات الاحتماعية في تنمية مفهوم الامن القومي الشامل لدى

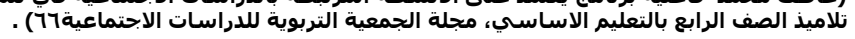


دـ - ويمكن للتعليم أن يكون أداة فعالة في بناء المجتمعات على أساس من السلم

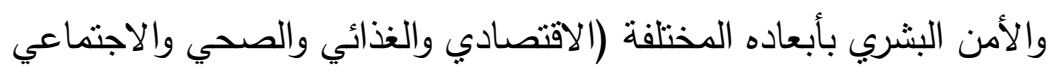

$$
\text { والبيئي والثخصي والنينياسي). }
$$

هـ- التعليم استثمار في البشر وله مردوده الاقتصادي والاجتماعي والثقافي في عالم البوم السريع التغير والذي أصبح فيه البقاء للأذكى.

و - التعليم في التراث الإسلامي جزء مكمل لشخصية الفرد وهو فريضة تعبدية

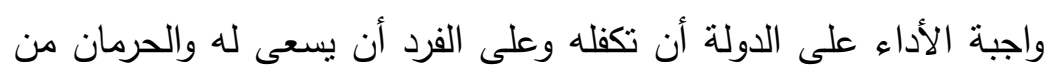

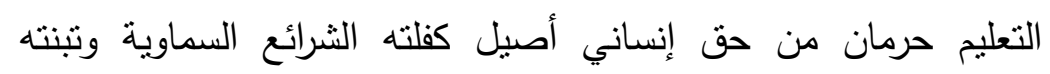

$$
\text { الحضارات الإنسانية. }
$$

- وباختصار ، فإن التعليم هو المحفز للأمن والتتمية باعتبارهما وجهين لعملة واحدة

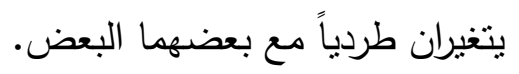

• r - وهكذا يتعاظم دور علاقة المؤسسات التعليمية في عالم اليوم الذي بشهد نزوحاً منسارعاً نحو العولمة مع الأجهزة الأمنية المختلفة.

المحور الثالث: - n

التجرية المصرية اليابانية وعلاقتها بتطوير التعليم:

\section{أ-جذور النظام التعليمي في البإبان (ץ):}

ترجع جذور النظام التعليمي الحديث في اليابان إلى عصر الإمبراطور

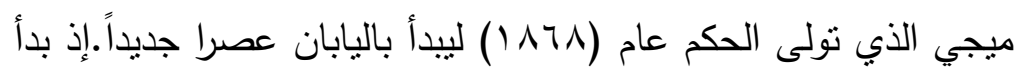
يبني اليابان الحديثة بعد أن رزحت البلاد حوالي ثلاثمائة عام تحت حكم الإقطاع. ولقد أصدر هذا الإمبراطور وثيقة وصفت بأنها تاريخية ونجحت هذه الوثثقة في إثارة المشاعر الوطنية حيث طالب بتوزيعها

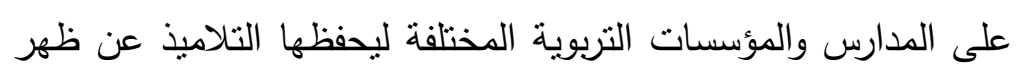


قلب ولقد أكد فيها على أهمية العلم حيث أوصى اليابانيين بطلب العلم

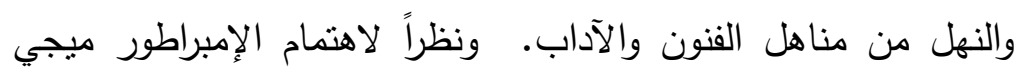

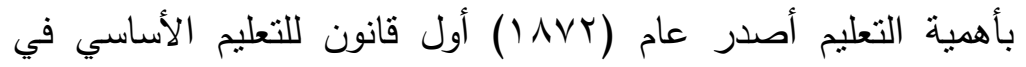

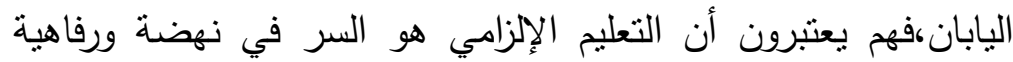
اليابان.

ولقد بدأ تعميم نظام التعليم الإجباري بصورة جدية،ففي سنة ( .9 (1)

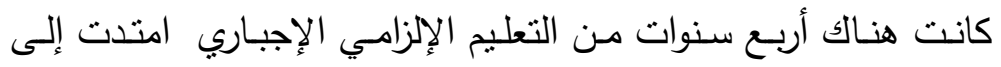

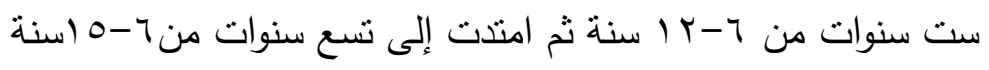

ب- الملامح الأساسية للنظام التعليمي في اليابان :

حتى نلم بكافة أبعاد الدور الذي تقوم بـه المؤسسـة التعليمية في تشكيل حياة إنسان

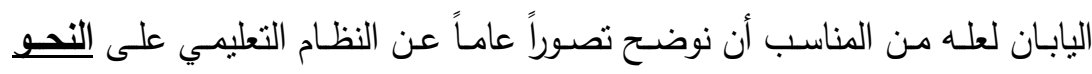

التالي:(')

يقوم النظام التعليمي في اليابان والذي يستوعب مائة في المائة من

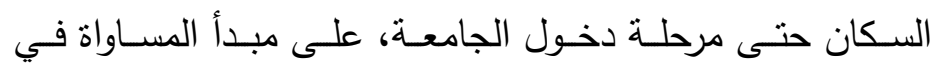

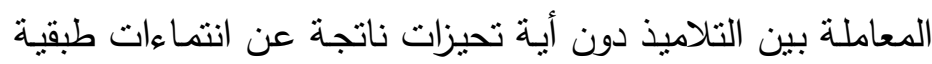
أو خلفيات عائليـة أو قدرات ذهنيـة، والافتراض الأساسي للنظـام التعليمسي هو أن كافـة التلاميذ يتسـاوون في القدرات ويسأتي دور المعلم في تتمية كافة القدرات بشكل متوازن بين الجميع • لنعان نتيجة لهذا الافتراض الأساسي بالمساواة فإن الانتقال من مرحلة

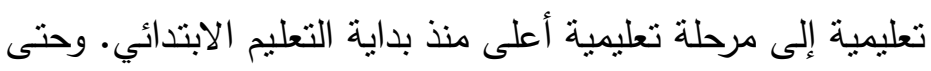

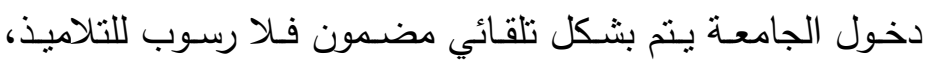

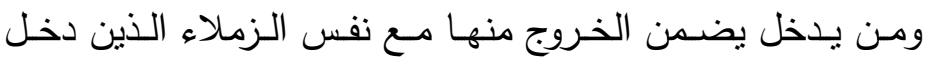

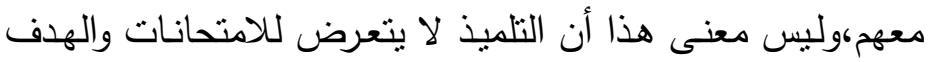


مـن الثقييمات الدوريـة هـو التأكيد من أن المعلم قد حقق هدف التوازن في توصيل المعرفة وتتمية القدرات بين مختلف التلاميذ. عند مستوى التعليم الجامعي يختلف الوضع فيما يتعلق بالمساواة

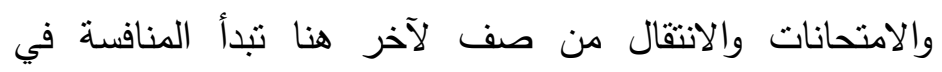

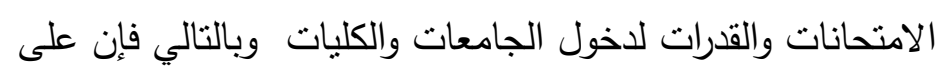
الطالب أن يختار عدداً من اختبارات القدرات التي تعكس إمكاناته

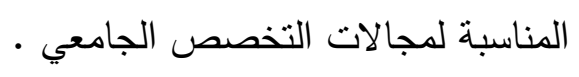
- السلم التعليمي في المدارس اليابانية(؟) كان نظام التعليم قبل الحرب العالميـة الثانيـة يتشـب إلى خمسـة فروع بعد ست سنوات من التعليم الأولي :

أ- أهمها الفرع الأكاديمي إذ كان يحظى بمكانة كبيرة لأنه يؤدي إلى الى اله

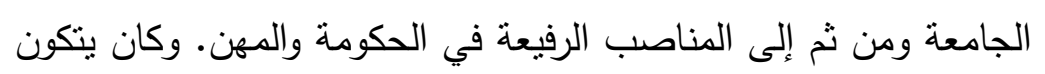
هذا النظام التعليمي الراقي من خمس سنوات بعد التعد التعليم الأولي في

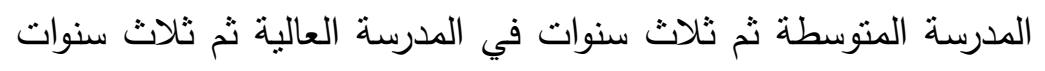

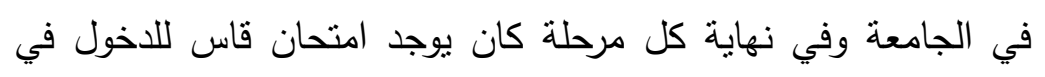
المرحلة التالية.

ب- وهناك نظام تعليمي آخر للبنات بصفة خاصة، وذللك لأن الفلسفة

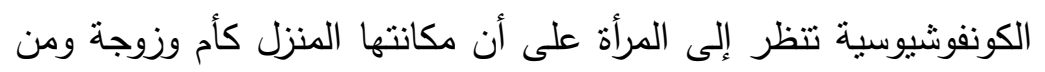

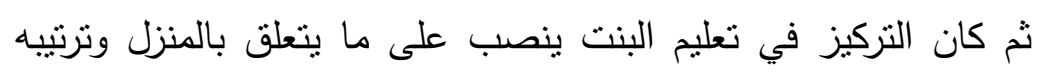

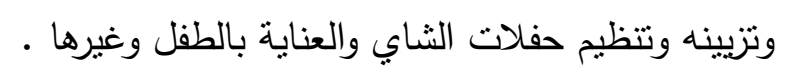

ج- - النظام التعليمي الثالث : يستهدف إعداد الددرسين المخلصين للإمبراطور

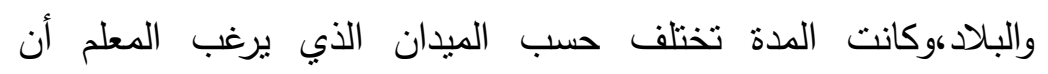


يتخصص فيه، وكانت الحكومة تذفع نفقات التعليم وفي مقابل ذلك كان

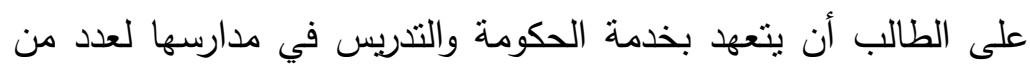

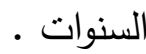

د- أما النظام الرابع فهو نظام التعليم الفني لمدة خمس سنوات بعد التعليم الأولي

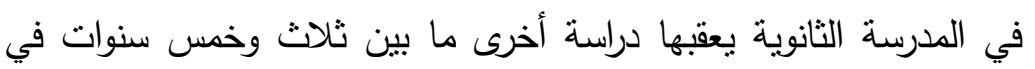
المعاهد الفنية العالية، وكان التعليم الفني يعد الطلاب للعمل في المهن لهن المتوسطة في الزراعة والصناعة والتجارة .

هـ - والنظام الخامس هو مدارس الثباب وكانت توفر تعليماً على أساس

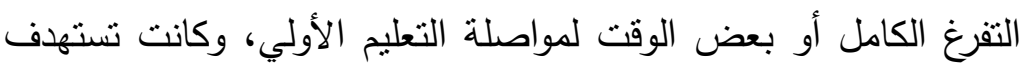

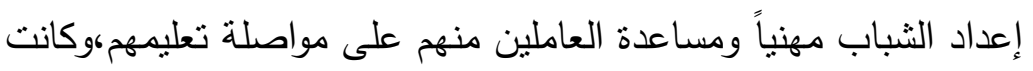
مدة الدراسة تتراوح ببين سنتين وسبع سنوات، وكانت الدراسة تتركز حول الزراعة أو الصناعة أو صيد الأسماك، وخلال الحرب العالمية الثانية

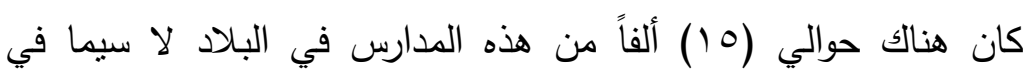

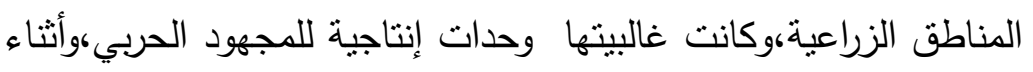
تلاك الفترة وضعت هذه المدارس تحت إثراف الجيش واستخدمت لخدمة أغراضه وهكذا كان نظام التعليم في اليابان يعكس النظام الاجتماعي

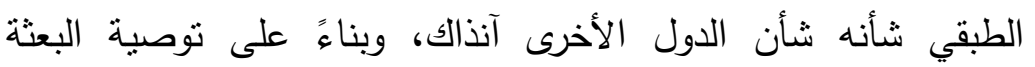
التعليمية الأمريكية أعبد تتظيم التعليم الياباني على أساس توحيده في النياء

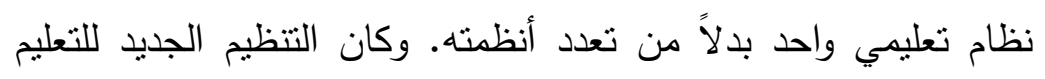

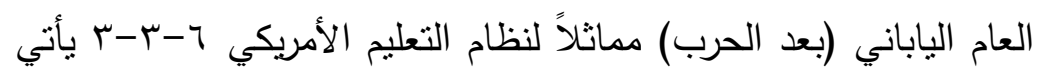
بعد ذللك مرحلة الجامعة ومدة الدراسة بها أربع سنوات.

- ويبدأ السلم التعليمي بمدارس الحضانة ومدارس رياض الأطفال ثم تأتي بعد ذلك

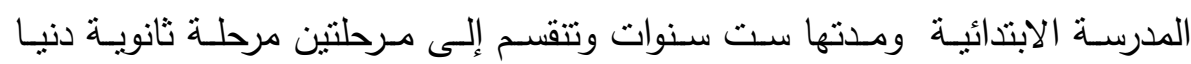
ومرحلة ثانوية عليا وكل منهما ثلاث سنوات. 


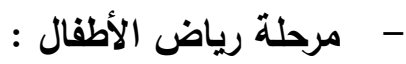

أ- تعتبر رياض الأطفال من المؤسسات التربوية بالغة الأهمية , فهي تشتقبل

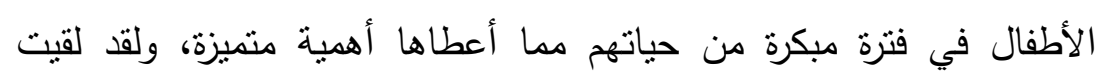

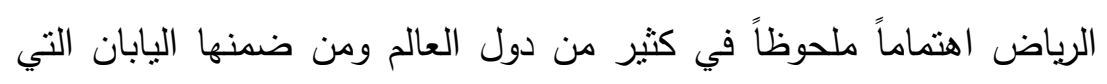

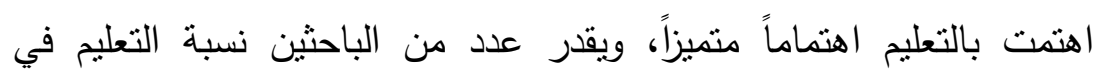

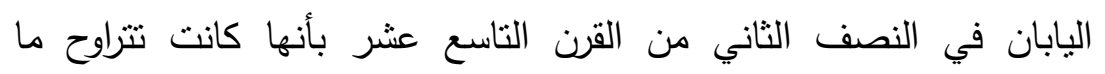

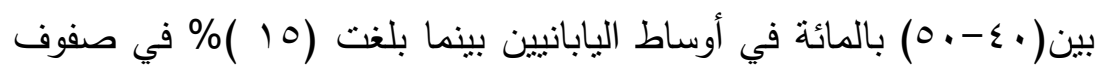

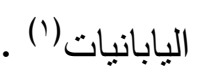

ب- - ولقد اعتبر بعض الباحثين أن التربية اليابانية تأني في طليعة التفسيرات

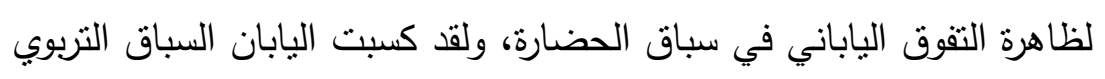
وهذا ما توصلت إليه أحدث الدراسات الأمريكية عن اليابان.

ج- وبيدأ السلم التعليمي برياض الأطفال، ويقبل الأطفال الذين نتراوح أعمارهم ما بين ثلاث إلى خمس سنوات وتترف عليها السلطات التعليمية الوطنية والإقليمية،وإلى جانب الرياض هناك مدارس الحضانة النهارية، وهي مؤسسات

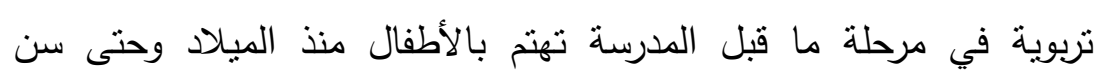
الخامسة ممن هم في حاجة إلى رعاية اجتماعية، وتترف علئه ماليها هيئات الرعاية الاجتماعية على المستوبين الوطني والمحلي (كاج).

د- ـ وعلى الرغم من أن مرحلة التعليم في رياض الأطفال في اليابان مرحلة اختيارية إلا أن شعبيتها في تزايد مستمر بوصفها الدرجة الأولى في سلم النظام التعليمي، ورياض الأطفال في اليابان تقدم مقررات للأطفال خلال

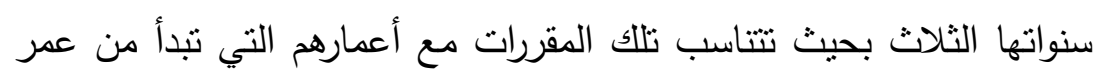

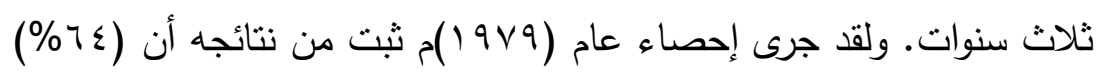
من الأطفال الذين تتراوح أعمارهم بين الثالثة والخامسة كانوا ملتحقين بهذاء 


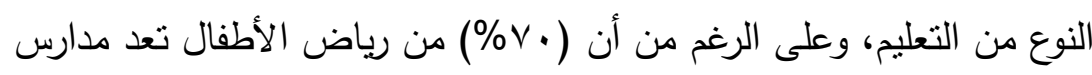

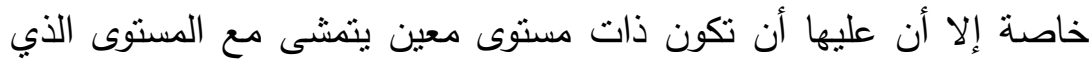
حددنه وزارة التربية هنالك، وذلك بناءً على نصائح (المجلس القومي لمناهج

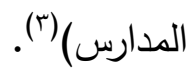

\section{- اليوم المدرسي ومجالات الدراسة(') -}

أ- هناك مجالات ستة للاراسة في رياض الأطفال في جميع أنحاء اليابان وهذه

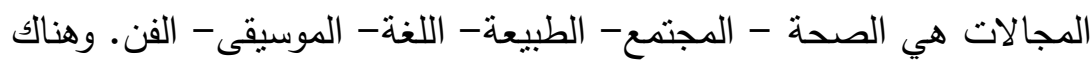
بديل لرياض الأطفال يتمثل في مدارس الحضانة والتي لديها برنامج مشابه لبرنامج رياض الأطفال و لكنه يجري بإشراف من وزارة الخدمة الاجتماعية. ب- أما اليوم المدرسي في رياض الأطفال فيبدأ في الثامنة والنصف صباحاً، حيث يفتحون يومهم بفترة من اللعب الحر مع إثراف محدد من مدرستهم التي

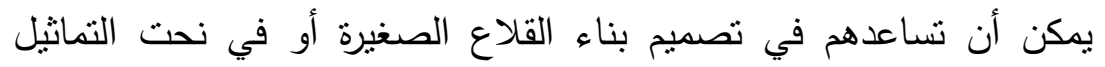
واللعب في صناديق الرمال أو قد تثاركهم اللعب في الأرجوحات بالمدرسة،

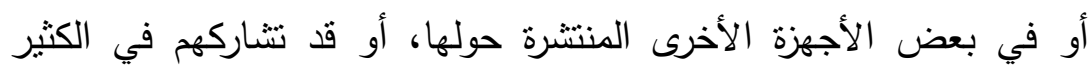

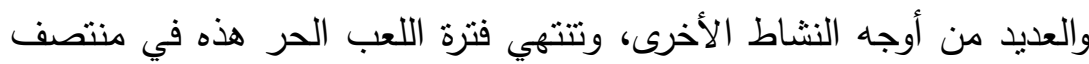

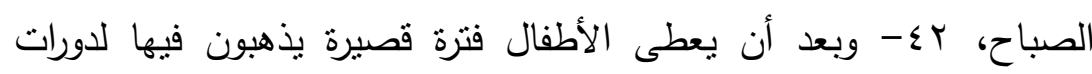

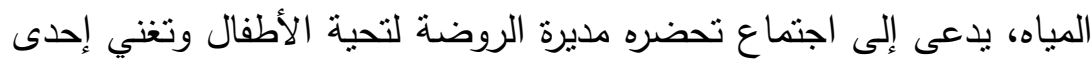
الأغنيات المدرسية ويعقب ذلك عمل مدرسي جاد بواسطة المعلمات وبعد تتاول طعام الغذاء يمنح الطلاب نصف ساعة للعب الحر وبعد لحظات يجمعون حاجاتهم وينظفون حجرات دراستهم ويعودون في الواحدة ظهراً. 
مرحلة التعليم الابتدائي(؟):

أ- ومدة الدراسة فيها ست سنوات من سن (7- ا I ) ويهتم الثعب الياباني بدخول

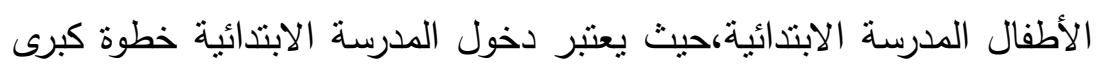

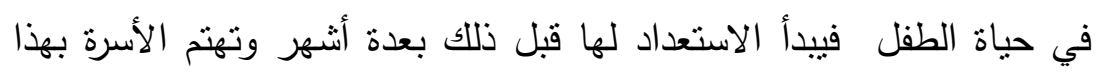

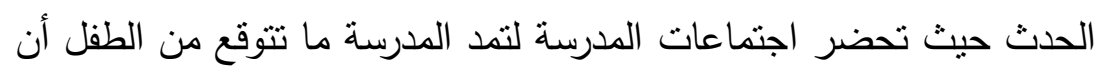

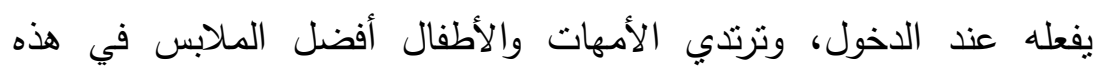
المناسبة وينضم طلاب الخامس والسادس في الترحيب بالتلاميذ الجدد

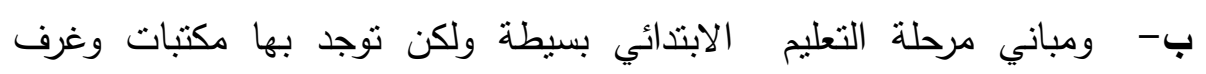

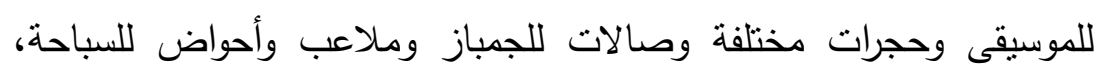
ومعظم المدارس الابتدائية لها زي ويكتفي بشيء بسيط يشير للمدرسة التي يتعلم بها.

- فلسفة التعليم الابتدائي(r): يتم النقل للصف التالي تلقائياً وليس على أساس الإنجاز الأكاديمي ويتم تعويد الطفل في بداية العام بعض العادات باستخدام برامج التلفزيون التعليمية وتعقد امتحانات تحريرية وتعطى واجبات منزلية روتينية. - وهناك فرق شاسع بين نظام الترفيع التلقائي في اليابان وفي مدارسنا حيث نجد أن الطلاب

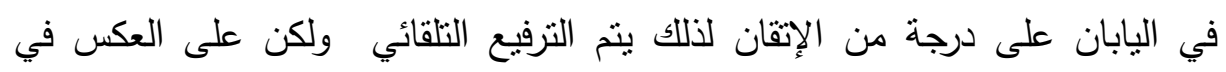

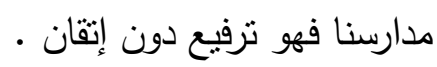

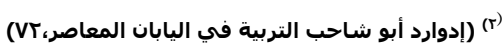
(www.saudiembassy.or.jp/Ar/Education/Ed_n_jp_Car.ht) ${ }^{(r)}$ 


\section{- مناهج الاراسةة: (') - من -}

يؤكد اليابانيون على تعليم العلوم والرياضيات طوال مرحلة التعليم الابتدائي والثانوي لاعتقادهم أنها البنية الأساسية للتكنولوجيا، فيتعلم اليابانيون اللغة اليابانية التي تتميز لتهيز

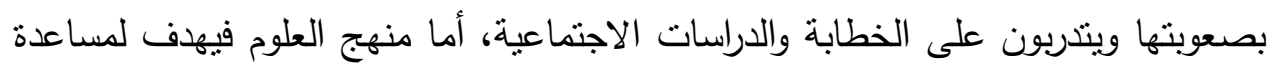
الطفل على تتمية القدرة على الملاحظة والتجريب وعلم التشريح وفي نهاية الصف السادس وله يكون الطالب قد تعلم تصميم وتتفيذ التجارب البسيطة وتسجيل ملاحظاته، ويتعلم الطفل

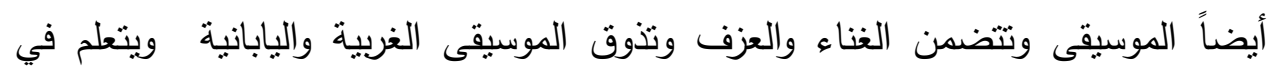
الصف السادس الحفر على الخشب كما تلقى التربية الرياضية الاهتمام من الحكومة.

- أهم ملامح وخصائص نظام التعليم الياباني(؟) من خلال العرض الساب يمكن إيجاز أهم الملامح التي تميز التعليم في اليابان في النقاط التالية:

$$
\text { أ- المركزية واللامركزية في التعليم. }
$$

ب- روح الجماعة والعمل الجماعي والنظام والمسؤولية. ج- الجد والاجتهاد أهم من الموهبة والذكاء.

$$
\text { د- الكم المعرفي وثقل العبء الدراسي. }
$$

هـ الحماس الثديد من الطلاب وأولياء الأمور للتعليم وارتفاع المكانة المرموقة للمعلم.

ץ- الاستفادة من التجربة الياباتية لإصلاح التعليم في مصر(") يعتبر النظام التعليمي في مصر نظاماً مركزياً يخضع لسبطرة الحكومة ويقوم نظام

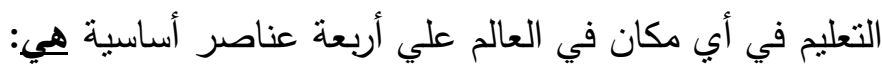




$$
\text { د- ج- أمعلم. - المدرسة أو الجامعة (مكان تلقي العلم) }
$$

- يعاني نظام التعليم المصري بكل عناصره وبكل مستوياته منذ أمد بعيد من العديد من المشاكل والتحديات والتي تمثل عائقاً حقيقياً أمام العملية التعليمية وتطورها وبالتالي التحدث

والتتمية الثاملة.

- مشاكل التعليم في مصر هي مشاكل بالغة الخطورة نظراً لكونها متعددة الجوانب في تلازم الحاور الأربعة السابقة للعملية التعليمية وذلك كما يلي:

\section{أ-بالنسبة للمعلم:}

المعلم غير مؤهل تعليمياً وتربوياً بالثكل الصحيح.

تدني العائد المادي الذي يحصل عليه المعلم بما لا يكفل له حياة كريمة، مما يجعل المعلم يستشعر الحرج ويقلل من قيمة نفسه عندما يطلب من التلاميذ في الفصل أن يعطيهم دروساً خصوصية. بعض المعلمين ليسو قدوة حسنة للطلاب.

يكرس المعلم معظم وقته ومجهوده للاروس الخصوصية ووجوده بالمدرسة يكون مجرد وظيفة فقط خاصة في مرحلة التعليم الثانوي التي أصبحت كابوس مزعج للعديد من الطلبة والأسر المصرية، حيث أنها

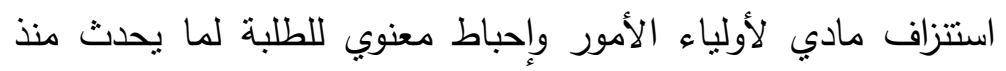
سنوات من حالات غش وتسريب للامتحانات وبالأخص في الثانية العامة، وعلي الرغم من تعاقب وزراء عديدين للتربية والتعليم بحكومات عديدة بمصر لم يتم حل تلك المثكلة. 


\section{ب-بالنسبة للطالب:}

(1) يفقد الطالب الثقة في قيمة التعليم وخوفه علي مستقبله.

(r) يعتمد الطالب اعتماد كلي علي الدروس الخصوصة نظراً لما يلاقيه من اهتمام من المدرس أثناء تلك الدروس أكثر من اهتمامه به داخل الفصل

$$
\text { الدراسي. }
$$

(r) يعجز الطالب علي إخراج ما لديه من قدرات ومواهب قد لا تكون لدي غيره.

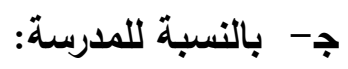

(1) ضعف الإمكانات والوسائل العلمية المنوفرة في الددرسة نتيجة قلة الدعم

$$
\text { والتمويل المتاح للمدارس. }
$$

(r) التكلس الطلابي الكبير داخل الفصول، حيث يحتوي الفصل علي أكثر من

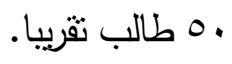

(T) عدم وجود معامل علمية مجهزة بالمدارس لخلق جو من الابتكار لدي

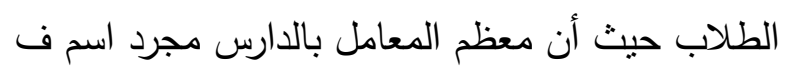

\section{د- بالنسبة للمناهج التعليمية:}

(1) الاعتماد علي الحفظ والتلقين فقط، حتي في المواد العلمية كالإحصاء

$$
\text { والرياضيات الفيزياء. }
$$

(r) الحشو في المناهج التعليمية دون التركيز علي النقاط التي تتمي ذكاء الطالب وتجعل منه مبدعاً، مما يدفع التلاميذ إلي البحث عن الكتب لئب

$$
\text { الخارجية. - (الطابة }
$$

$$
\text { (r) اعتماد المناهج علي الجانب النظري فقط. }
$$

( ) عدم ملائمة المناهج للتطور العلمي وأعمار الطلاب. 


\section{المجلة العلمية لكلية رياض الاطفال - جامعة اسيوط}

- هذه هي أهم المشاكل التي يعاني منها التعليم في مصر علي الرغم من احراز تقدم

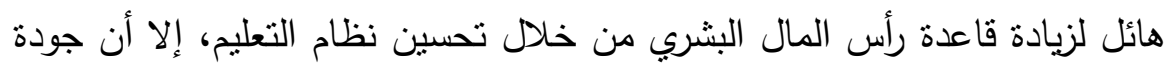

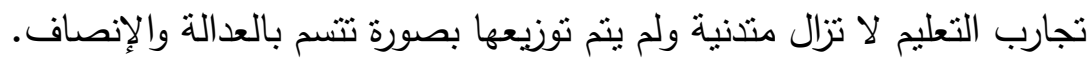
- ذا نجد أن التجربة اليابانية في مجال التربية من أفضل التجارب علي مستوي العالم، حيث أصبح من الضروري أن نطور نظامنا التعليمي بحسب ما دانجيه انتهينا إليه

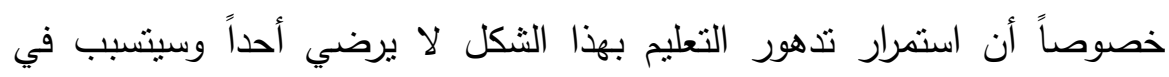

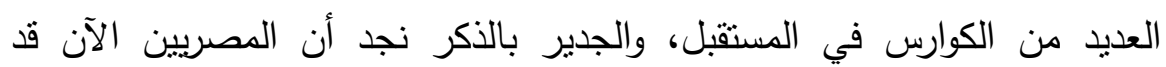

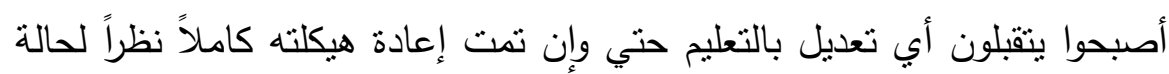
التدهور الثديد التي أصابته.

- وليس من العيب أن نتعلم من تجارب النتمية باليابان والدول المثقدمة خاصة وأن اليابان

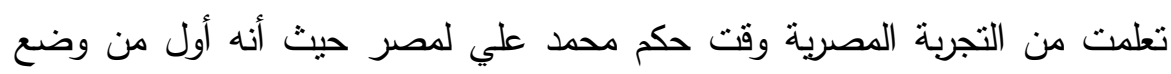
نهضة للتعليم بمصر .

- - ولقد أصبح رؤساء كثثر من الدول يعلنون صراحة أن التعليم هو الركيزة الأساسية

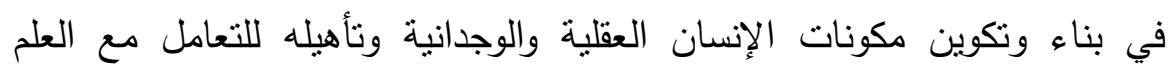

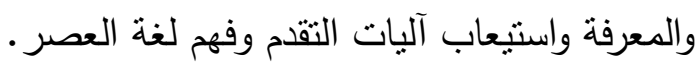

- - ملقد أبدي السيد الرئيس تقديره بالاهتمام الخاص بالتعليم في اليابان والدروس التي يمكن لنا أن نتعلمها من تجربتها في التعليم، ولقد اتجهت الأنظار نحو تطبيق لتيق النهضية

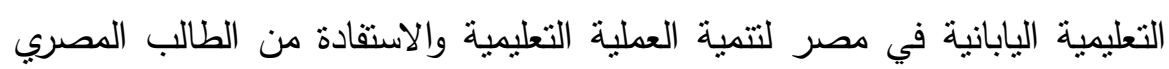

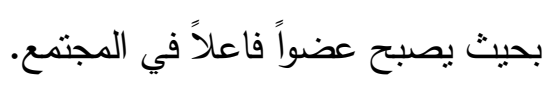
- وهذا ما أكده نربيون بضرورة إعادة تكوين الثخصية المصرية وتربيتها من جديد

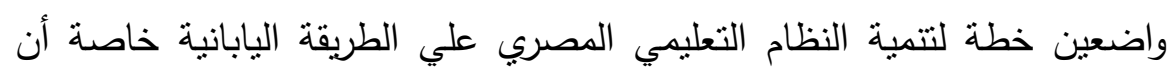
التجربة اليابانية في مجال التربية من أقضل التجارب علي مستوي العالم. - وذللك لأن منـاهج التعليم اليابانى أصبحت اليوم من المناهج العالميـة التى تتظر إليها وتحاول تقليدها الأمم الأخري. 
- وأن الطفل اليابانى يحصل على نتائج عاليـة فى الاختبارات الدولية التى تقبس القدرات

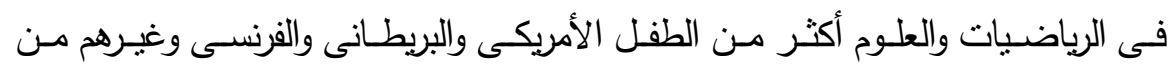

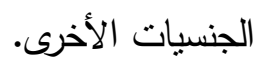

- وأن سر نهوض اليابان هو الاهتمام بالمورد البشرى وتتميته من خـل تغيير نمط

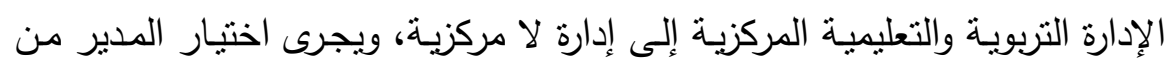
مستوى شهادة إكمال الدراسة فى مؤسسات إعداد المعلمين. - - متطييق أهداف التربية، منها النمو الكامل لثخصية الفرد من أجل رفعـة وتقدم

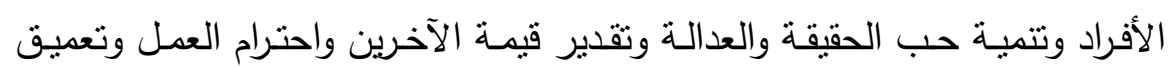

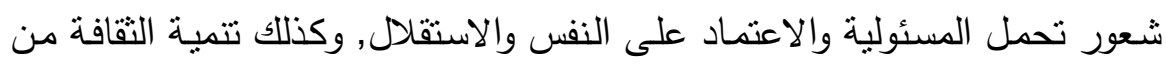
خلال الاحترام المتبادل والتعاون واحترام الحرية الأكاديمية والحياة الواقعية. ع -عناصر نجاح تطبيق أنشطة التوكاتسو في المدرسة المصرية اليابانية : لابد من نوافر سبعة عناصر لنجاح تطبيق أنشطة التوكاتسو في المدرسـة المصرية اليابانية،

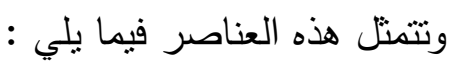
ا ـ فلسفة واضحة نؤمن بها المدرسة . r • رؤية محدد ومعلنة تشير إلى الطموح المراد الوصول إليه . r. خطة إستراتيجية تلبي احتياجات المستقبل ويمكن تطبيقها. ع. مهارات العاملين ملبية لاحتباجات العمليات التربوية والتعليمية وفق تطبيق أنشطة التوكاتسو . هـ موارد مالية وبشرية ملبية لمتطلبات تطبيق انشطة التوكاتسو . 7. V. ت نظيم إداري يحقق متطلبات أنشطة التوكاتسو . 
ولنجاح تجربة نظام التعليم الياباني فى مدارس التعليم الاساسى المصرية.

يجب ان يتم التاكيد على الأبعاد التالية :

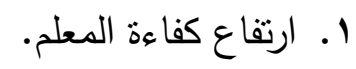

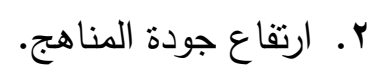

r. المستوى التعليمى للطالب كمنتج تعليمى.

ـ. ـ مدى ملائمة المنتج التعليمى لسوق العمل.

,ونرى تجربة ناجحة أمامنا فى النموذج اليابانى يمكن أن نضعها نصب أعيننا وهى

(مدرسة وادا الإعدادية) شعار المدرسة معلق في مكتب المدير .

ولعل الهُف من إدارة هذه المدرسة- أو ما يسمى بالرؤية التعليمية - يكمن في

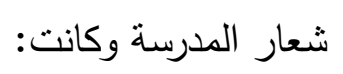

"الحكم الذاتي والمساهمة: كرس نفسك ايها التلميذ والطالب لتحقيق أحلامك

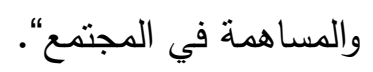

وبالنظر إلى الأوقات الصعبة التي نعيشها حالياً، فإنّ وجود الآمال والأحلام ليس بالأمر السهل بالنسبة للكثير من الأطفال.

فعلى الرغم من أنهم قد يتعرّضوا للهزيمة أو خيبة الأمل، فإننا نريد منهم التمسك

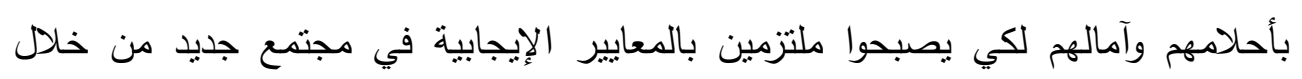
التقكير والعمل لأنفسهم. هذا الهدف يكمن في صميم كل جهودنا.

فإنه من الأهمية بقدر أن يبدأ كل واحد من التلاميذ في التفكير بجدية في الحياة

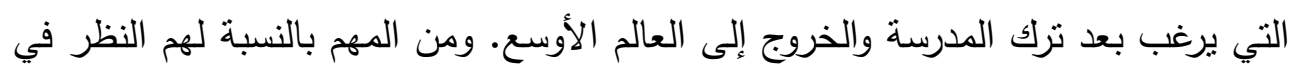
احتياجات المجتمع بدلا من التركيز على مصالحهم الذانية نفسها. 
ونحن نعتقد أنه من المهم أيضا تعليم الأطفال مراعاة مشاعر الآخرين وتتمية

الوعي، وهذا لا يعني التضحية بالنفس بالضبط، ولكن أهمية القبام بأثنياء تُسهم في اسعاد التهن الآخرين.

وكان لايهم دائماً في مدرسة وادا رؤية واضحة لنوعية الطلاب الذي يسعوا

لتخريجهم.

وهذا هو أحد الأسباب التي تجعلهم موفقين في تنفيذ إصلاحات كثيرة. ويعملوا بجد

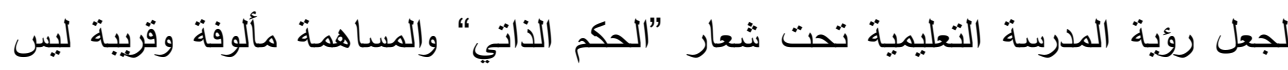
للطلاب والمعلمين فقط، وإنما للآباء والأوصياء أيضاً بالإضافة الى غيرهم من المجتمع المحلي.

هذا جزء حاسم من أجل فهم الناس لهم وكسب الدعم الضروري لتحقيق أهدافهم

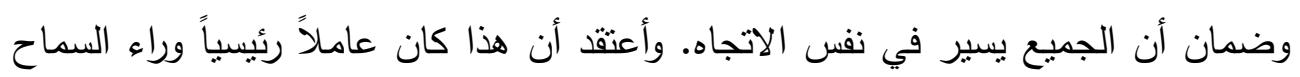
لهم بإنجاز برنامجهم الإصلاحي بشكلٍ سلس.

وفى حالة قمنا فى مصر بهذه المنهجية فى التطبيق بمكننا أننا نقول أننا على بداية الطريق الصحيح وبالفعل بدأنا فى مصر وعينة النطبيق الحالية بمديريات التربية والتعليم (القاهرة_الجيزة-القليوبية).

لذا نجد أن النجاح يأني بسبب مجموعة من العوامل، منهج منوازن، ثقافة المدرسة

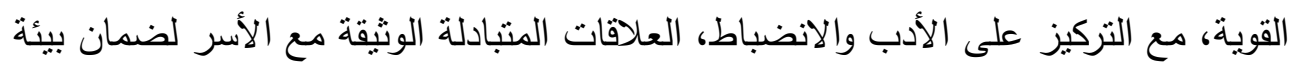

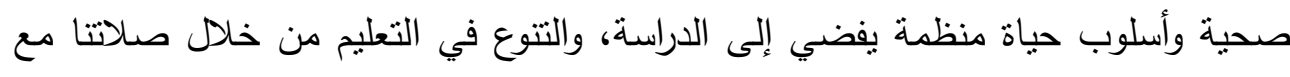
المتنمع المحلي.

ومن هنا نجد أن فى تطبيق أنشطة التوكانسو (النظام البابانى) أعظم الأثر فى

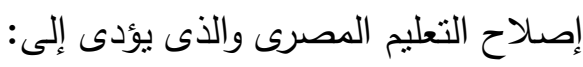


- ينظر التلاميذ إلى انفسهم على أنهم مفكرون

r - تتجيع التلاميذ على النظر بصورة موضوعية تجاه تفكيرهم وتقكير الآخرين

r- تقدير وإحترام الذات والثقة في القدرة على التفكير

ع - الأنشطة لا تعتمد على قدرة الطالب في التحصيل العلمي، فقد يكون

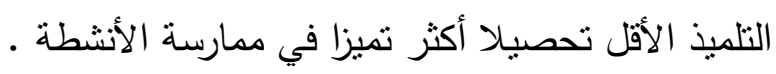

ه- تهدف الأنشطة إلى تعميق الولاء والإنتماء لدى التلاميذ تجاه المدرسة

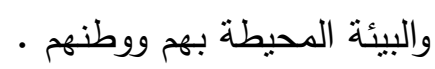

צ- الخروج من روتين التعليم الحالي ومن الإعتماد على الحفظ والتلقين إلى

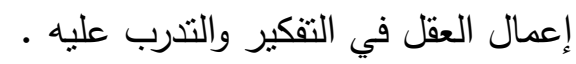

V - تمية قدرة التلاميذ على الإعتماد على الذات والعمل الجماعي وتتويع

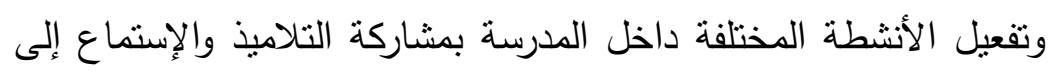
أرائهم المختلفة . والفيطة

1- تتمية قدرة المتعلم على التفاعل الإجتماعي والتواصل مع الآخرين (مهارات التواصل والعلاقات بين الأشخاص)

9- تتمية مهارات تقييم النتائج المستقلية وتحديد الحلول البديلة للمشكلات ـ العناية الثخصية بالجسم والملبس والادوات الثخصية ـ 1 1-إظهار أهمية مهارات حسن إستخدام الوقت في العمل المنتج r ا-تدريب التلاميذ على مهارات التفاعل مع الآخرين من خلال المناقثة

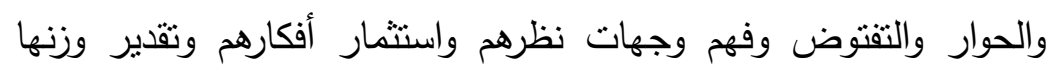
النسبي والاستفادة من الآراء البناءة للوصول وهئ لطرهم والى رؤية مشتركة . 


\section{ه -الخلاصة}

التعليم الأساسي هو تعليم موحد للجميع و مدته نسع سنوات يتلاءم مـع التوجهات التربوية الحديثة ويتصف بالآتي:

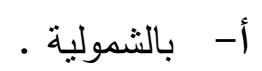

ب- يهتم بالربط بين النظرية والتطبيق والفكر والعمل والتعليم والحياة.

ج- يسعى نحو إكساب المتعلم مهارات التعلم الذاتي ويتصف بالمرونة في توجيه

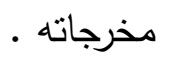

د- يهيئه للتدريب مـن أجل الالتحاق بسوق العمل , وفق استعداداته وإمكاناته

$$
\text { وكفاياته . }
$$

هـ يستهدف إعداد المتعلمين للإسهام في التتمية المجتمعية الثناملة .

- مفهوم الأمن القومي بوجه عام هو تحقيق منطلبات التتمية الثاملة الاجتماعية

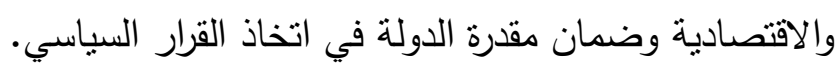

دور إستراتيجيات التعليم على الأمن حيث يعتبر التعليم أحد مفاتيح التتمية الرئيسة،

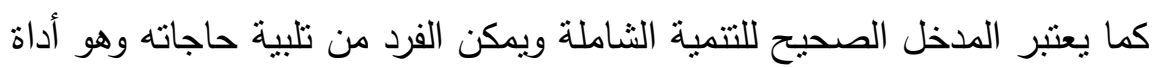

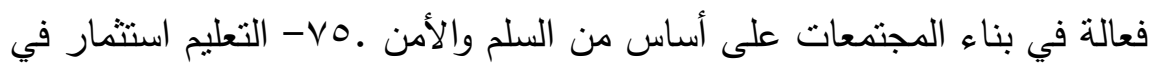
البشر وله مردوده الاقتصادي والاجتماعي والثقافي والتعليم في التراث الإسلامي هي

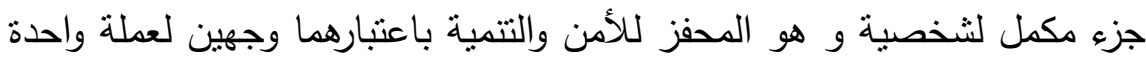
العلاقة بينهما تربية.

- يتعاظم دور علاقة المؤسسات التعليمية في عالم اليوم الذي يشهذ نزوحاً منسارعاً نحو العولمة مع الأجهزة الأمنية المختلفة. - الاستفادة من التجربة اليابانية لإصلاح التعليم في مصر وذللك من خلال ملامح وخصائص نظام التعليم الياباني . 


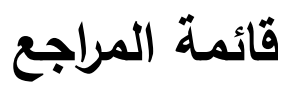

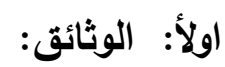

1. القرأن الكريم. سورة التوبة آية رقم ه. 1، سورة النمل آية رقم 11، سورة الكهف آية

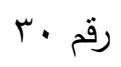

ثانيا الكتب العلمية العربية : ب إن

r. اكليب الجني المحدث :السيوطي_الدصدر الجامع الصغير, الدرر السنية لأهل

$$
\text { السنة ,ص1862. (186. }
$$

r. عائشة,المحدث،البوصيرى, المصدر :إتحاف الخيرة المهية,الدرر السنية لأهل السنة،

$$
\text { ص، 3/38 (n) }
$$

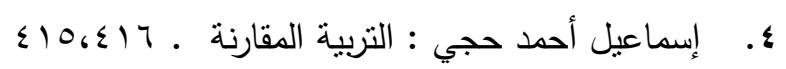

ه. - سنجلتون :الدرسة اليابانية .صه-7 .

$$
\text { ד. }
$$

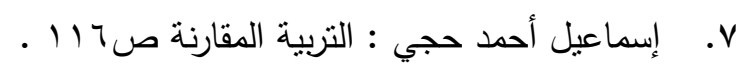

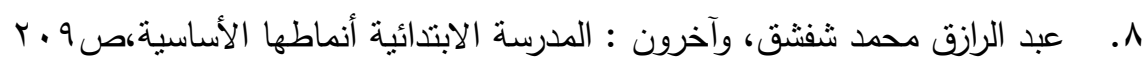
9. عبد الغني عبود : دراسة مقارنة لتاريخ التربية، صبror.

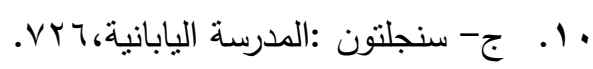

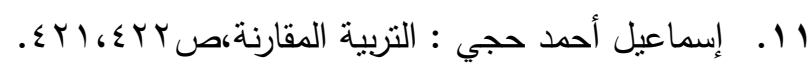

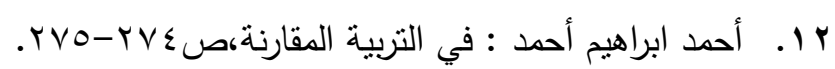

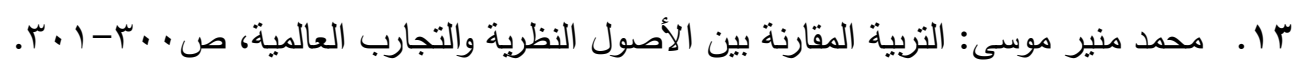
؛ ا. . عبد الغني عبود : التربية العربية الدقارنة منهج وتطبيق،صسم. هـ . محمد جابر الأنصاري : جذور التربية اليابانية، لون. 


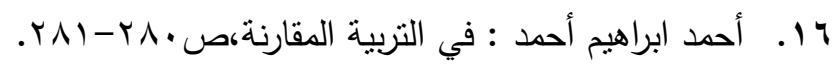

IV 11 ا. نفس المصدر :ص اع.

9 19. محمد عبد القادر حاتم : التعليم في اليابان، ص9 ץ.

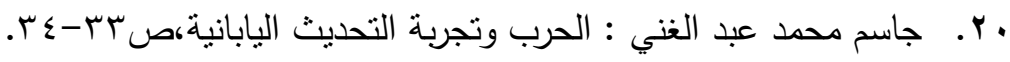
ا r. . محمد عبد القادر حاتم : التعليم في اليابان، 91. r r . . محمد منير موسى : المرجع في التربية المقارنة،صع ع. r r. أحمد إسماعيل حجي : التربية المقارنة،ص اس؟. ع r. . عبد السميع سيد أحمد : المربون العظام في البابان، وب. هץ. إدورد، أبو شاحب : التربية في اليابان المعاصر،؟؟. צ Y. أحمد إبراهيم أحمد : في التربية المقارنة، \ـ. V r . . سعد الدين إبراهيم وآخرون : مستقبل النظام العالمي وتجارب تطوير التعليم،صو ـ. ^ץ. ـ ادوارد، بو شاحب : التربية في اليابان المعاصر ، 9ء. q r. . محمد منير مرسي : المرجع في التربية المقارنة،صه . . • r. إدورد،أبوشاحب : التربية في اليابان المعاصر ،صع 7.

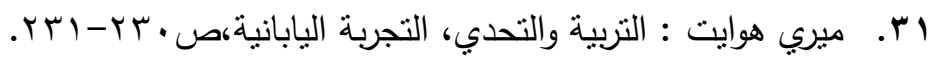
r.r. محمد عبد القادر حاتم : التعليم في اليابان،صه111. rr. عبد الغني عبود دراسة مقارنة لتاريخ التربية،ص Vه. ع r. محمد عبد القادر حاتم : التعليم في اليابان، صـV

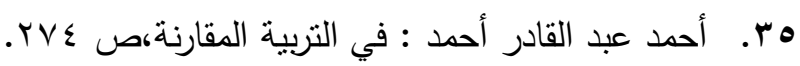
צr. ادوارد،بوشاحب : التربية في اليابان المعاصر ،صلVه. 


\section{المجلة العلمية لكلية رياض الاطفال - جامعة اسيوط}

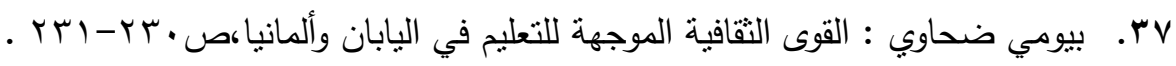

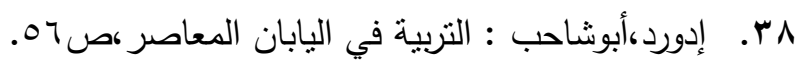
q ץ. إسماعيل احمد حجي : التربية المقارنة، صبrع.

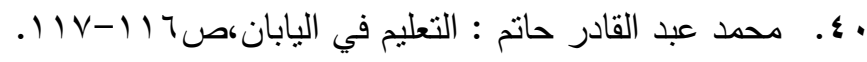

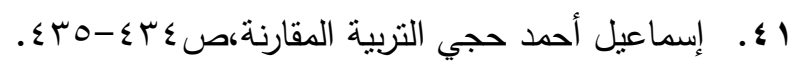
ץ ؟. محمد عبد القادر حاتم : التعليم في اليابان، ص1 • 1.

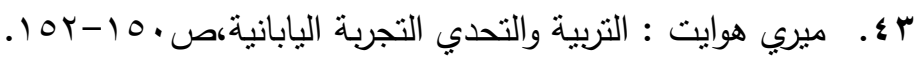

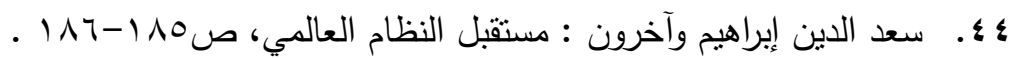
0 ؛. ميري هوايت : التربية والتحدي التجربة اليابانية، ص100.

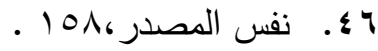

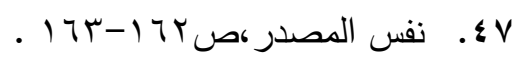
A ـ. محمد عبد القادر حاتم : التعليم في اليابان، صYVY-VY .

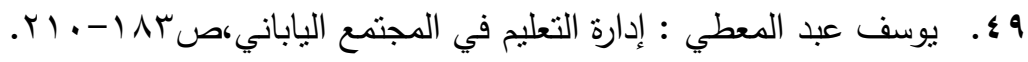

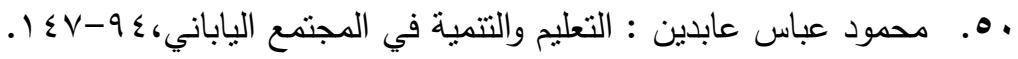

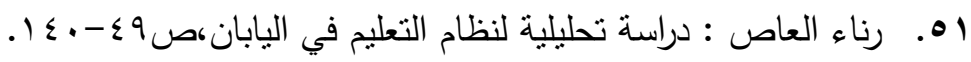

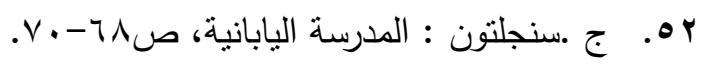

rه. محمود عباس عابدين : التعليم والتتمية في المجتمع الياباني،ص با. ؟ ه. يوسف عبد المعطي : إدارة التعليم في المجتمع الياباني،ص • ؟؟.

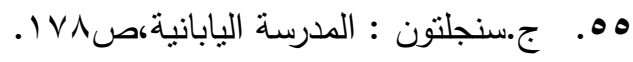

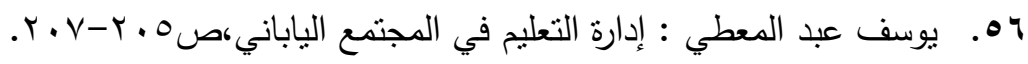

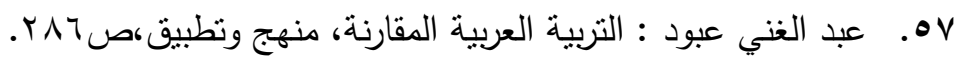


^ه ه. ربحي مصطفى عليان، محمد غنيم: "مناهج وأساليب البحث العلمي -النظرية والنطبيق"،

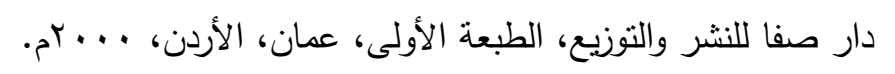

هـ ـ إحسان الاغا، ومحمود الأستاذ: "تصميم البحث التزبوي"، مطبعة الرنتيسي، الطبعة الثالثة،

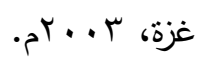

•. . جودت عزت عطوى: "أساليب البحث العلمي مفاهيمه، أدواته، طرقه الإحصائية"، دار

$$
\text { التقافة للنشر والتوزيع، القاهرة، } 9 \text {. . بم. }
$$

\section{ثانيا باللغة الأجنبية:}

1. Juran, M. (1992). Juran on Quality by Design: the Steps for planning Quality into Goods and Services, New York: the free press, p.36

2. C.D. (1986). Introducing Quality Assurance, London: King Fund s Center.

3. Crosby, Crosby, ph. B. (1979). Quality is free: the Art o Hill Book Co f Making Quality certain, New York: Mc Graw152

4. Deming, W. (1988). Quality, productivity, and Competitive Position, Cambridge, Mas: Massachusetts Institute of Technology,

5. Donabedian, A. (1985). Twenty years of research on the Quality of medical Care, Evaluation and the Health professions. vol. (8), no. (3).

6. Dressel, P.L. (1987). Handbool of Academic Evaluation, San Francisco: Jossey-Bass.

7. Gaucher, E.J. \& R.J. Coffey (1993). Total quality in Health-Care: From Theory to Practice, San Francisco: Jossey-Bass Inc. publishers.

8. Glassop, L. (1995). The road to quality, Sydney, Prentice hall, Australia, Itd. 
9. Ishikawa, K. (1985). What is Total Quality Control? The Japanese Way, Translated by David Lu, London: Prentice-Hall International.

10. Kaufman \& Hirumi, 1992: 34

11.Lam, K.D. et. al. (1991). Total Quality: A textbook of Strategic Quality Leadership and Planning, Colorado Springs: Air Academy press

12. Macchia , p. (1992 ).(Total Quality Education and Instructional System Development Educational Technology , July, 1992 